\title{
1 Endomembrane systems are reorganized by ORF3a and Membrane (M) of SARS-CoV-2
}

3 Yun-Bin Lee ${ }^{1}$, Minkyo Jung ${ }^{2}$, Jeesoo Kim³ ${ }^{3}$, Myeong-Gyun Kang ${ }^{1}$, Chulhwan Kwak ${ }^{1,5}$, Jong-Seo Kim ${ }^{3,4, *}$, Ji- $^{-}$

4 Young Mun ${ }^{2, *}$, Hyun-Woo Rhee ${ }^{1,4, *}$

5

$6{ }^{1}$ Department of Chemistry, Seoul National University, Seoul 08826, Republic of Korea

$7 \quad{ }^{2}$ Neural Circuit Research Group, Korea Brain Research Institute, 41062 Daegu, Republic of Korea

$8{ }^{3}$ Center for RNA research, Institute for Basic Science, Seoul 08826, Republic of Korea

$9{ }^{4}$ School of Biological Sciences, Seoul National University, Seoul 08826, Republic of Korea

105 Department of Chemistry, Ulsan National Institute of Science and Technology, 44919 Ulsan, Korea

12 *Corresponding authors:

14 Dr. Hyun-Woo Rhee

15 Email: rheehw@snu.ac.kr,

17 Dr. Ji-Young Mun

18 Email:jymun@kbri.re.kr.

Dr. Jong-Seo Kim

Email: jongseokim@snu.ac.kr, 


\section{Summary}

24 The endomembrane reticulum (ER) is largely reorganized by severe acute respiratory syndrome coronavirus 2 (SARS-CoV-2). SARS-CoV-2 ORF3a and membrane (M) protein expression affects ER-derived structures 26 including cubic membrane and double membrane vesicles in coronavirus-infected cells; however, the 27 molecular mechanisms underlying ER remodeling remain unclear. We introduced a "plug and playable" 28 proximity labeling tool (TurboID-GBP) for interactome mapping of GFP-tagged SARS-CoV-2 ORF3a and M 29 proteins. Through mass spectrometric identification of the biotinylated lysine residue $(\mathrm{K}+226 \mathrm{Da})$ on the viral 30 proteins using Spot-TurboID workflow, 117 and 191 proteins were robustly determined as ORF3a and M 31 interactomes, respectively, and many, including RNF5 (E3 ubiquitin ligase), overlap with the mitochondrialassociated membrane (MAM) proteome. RNF5 expression was correlated to ORF3a ubiquitination. MAM formation and secreted proteome profiles were largely affected by ORF3a expression. Thus, SARS-CoV-2 may utilize MAM as a viral assembly site, suggesting novel anti-viral treatment strategies for blocking viral 35 replication in host cells.

- SARS-CoV-2 proteins ORF3a and M alter endoplasmic reticulum proteome profile

- ORF3a affects mitochondrial-associated membrane formation

- SARS-CoV-2 may utilize mitochondrial-associated membrane as viral assembly site

- ORF3a and M interactome proteins may serve as targets for COVID-19 treatment

eTOC Blurb

ER remodelling by SARS-CoV-2 ORF3a and M protein 


\section{INTRODUCTION}

The ongoing pandemic of coronavirus disease 2019 (COVID-19) caused by the severe acute respiratory syndrome coronavirus 2 (SARS-CoV-2) necessitates detailed research into the molecular mechanisms underlying the ability of this virus to infect and colonize host cells. In particular, understanding the mechanism by which each viral protein encoded by the SARS-CoV-2 genome interacts with host factors is essential for the prevention or treatment of COVID-19. Similar to SARS-CoV and Middle East respiratory syndrome coronavirus (MERS), SARS-CoV-2 has been classified in the genus Betacoronavirus of the Coronaviridae family (Qin et al., 2005). It encodes 16 non-structural proteins (NSP1-16), 4 structural proteins (spike protein $[S]$, membrane protein $[M]$, envelope protein $[E]$, and nucleocapsid protein $[N])$, and at least 9 accessory proteins (ORF3a, ORF3b, ORF6, ORF7a, ORF7b, ORF8, ORF9b, ORF9c, and ORF10). The non-structural proteins are generated from an auto-proteolytic process and participate in the formation of the replicasetranscriptase complex, which is essential for the viral life cycle (Gordon et al., 2020). The structural proteins are components of each viral particle and are key factors in host cell infection (Gordon et al., 2020). The accessory proteins have functions associated with interferon and immune responses; for example, ORF3a of SARS-CoV activates the NOD-like receptor protein 3 (NLRP3) inflammasome (Siu et al., 2019), and ORF3b of SARS-CoV-2 acts as an interferon antagonist (Konno et al., 2020).

A previous study has demonstrated viral protein-host protein interactions of SARS-CoV-2 using a coimmunoprecipitation (Co-IP) method followed by mass spectrometry analysis (Gordon et al., 2020). The CoIP can show interaction partners with strong binding affinity to the viral proteins of interest (vPOI); however, these interactome data may also include artificial protein-protein interactions that do not occur in cells since these experiments are conducted using cell lysates isolated in artificial lysis buffer conditions. To overcome these limitations, proximity labeling (PL) methods have recently been developed, which are based on an enzymatic biotinylating reaction using in situ-generated reactive biotin species by genetically expressed enzymes. Examples of these enzymes include engineered ascorbate peroxidase (APEX) (Rhee et al., 2013), promiscuous biotin ligase (BioID) (Roux et al., 2012), and TurboID, which is an engineered biotin ligase with faster kinetics (labeling time less than $30 \mathrm{~min}$ ) (Branon et al., 2018). Since the biotinylation reaction induced by the PL enzymes occurs in living cells, and the labeling radius of the reactive biotin species (biotin-phenoxy 
radical and biotin-AMP) is less than $50 \mathrm{~nm}$, mass spectrometry analyses of endogenous proteins biotinylated

by the PL enzymes can accurately reflect the physiological interactome of the POI that is genetically expressed alongside these enzymes.

PL is being used to identify the host interactome of viral proteins, including coronaviruses (V'Kovski et al., 2019) and SARS-CoV-2 (Laurent et al., 2020; Samavarchi-Tehrani et al., 2020; St-Germain et al., 2020). Although this method shows various important host proteins that support viral life cycles (such as eIF3 and eIF4 complexes) and anti-viral proteins (such as MAVS, PKR, and LSM14A/B), the results from this technique may contain false positive findings due to the conventional mass detection workflow. Currently, most PL studies (including the viral interactome studies) have used conventional mass detection of nonbiotinylated peptides of the streptavidin-bead (SA-bead) enriched proteins from the PL-labeled cell lysate. However, this workflow can misidentify artificial interacting proteins in the lysis buffer as biotinylated proteins (false positive) when those proteins are reproducibly shown in the biotinylated samples over the controls. Furthermore, recent reports describing the mapping of the SARS-CoV-2 interactome (Laurent et al., 2020; St-Germain et al., 2020) utilized BioID, which performs slow biotinylating reactions on proximal proteins over a 12-h period. This long biotinylation reaction may perturb the physiological conditions of host cells.

To maximize the advantages of recently improved PL methods, in this study, we combined TurboID, a fast biotinylating enzyme (Branon et al., 2018), with the Spot-BioID method (Lee et al., 2019). In this technique, cell lysates are digested with trypsin followed by SA-bead enrichment at the peptide level, so that only peptides modified by TurboID with biotin-conjugated lysine $(\mathrm{K}+226)$ are detected using mass spectrometry. We further assessed the ability of our modified PL method, dubbed Spot-TurboID, to analyze proteins biotinylated by TurboID, and to ultimately obtain in vivo host interactome information without false positive results.

In the present study, we aimed to identify which proteins located near the endoplasmic reticulum (ER) interact with SARS-CoV-2 proteins, as the ER membrane is proposed to be the primary replication site for SARS-CoV such as SARS-CoV-2 (Stertz et al., 2007). Folding and synthesis of membrane, lipids, secretory proteins, sterols, and ion storage occurs in the ER (Lin et al., 2008). Among SARS-CoV-2 proteins, ORF3a is associated with vesicle sorting and fusion mechanisms while the $\mathrm{M}$ protein interacts with membrane-shaping 
proteins (St-Germain et al., 2020). Therefore, we focused on the ORF3a and M proteins, using our modified

PL system to examine their functions in living cells. We conducted correlative light and electron microscopy

(CLEM) imaging experiments to determine the localization and targeting sites of these proteins in living cells.

These findings can offer new research directions to improve our understanding of the mechanisms underlying

SARS-CoV-2 infection and to identify new therapeutic targets for COVID-19.

\section{Results}

\section{GFP-tagged SARS-CoV-2 structural and accessory proteins target specific organelles}

To confirm the subcellular localization of the SARS-CoV-2 proteins, we prepared 11 constructs of vPOIs

(NSP7, NSP8, NSP9, M, N, ORF3a, ORF3b, ORF6, ORF7b, ORF9b, and ORF9c) tagged with GFP using a 13-amino acid linker (GAPGSAGSAAGSG) (Figure 1A). Confocal imaging of HEK293-AD cells showed

that the GFP-tagged vPOIs were well expressed (Figure 1B). Compared with non-structural proteins,

structural and accessory proteins targeted specific organelles. NSP7, NSP8, and NSP9 showed a whole-cell

interact with a certain organelle, possibly due to the lack of viral RNAs. In contrast, M, N, ORF3a, ORF3b,

ORF6, ORF7b, ORF9b, and ORF9c showed organelle-specific localization patterns, indicating that these

proteins interact with host cell proteins of specific organelles. Among these constructs, we observed that the

expression patterns of ORF3a and M merged well with an ER marker protein, SEC61B (Figure S1A).

In line with a previous study showing that $\mathrm{N}$ protein is associated with stress granules (Gordon et al., 2020), confocal imaging of HEK293-AD cells co-expressing N-GFP and G3BP1-V5 (stress granule marker protein) (Anderson and Kedersha, 2006; Nover et al., 1983), showed that the two patterns clearly merged, representing a stress granule pattern (Figure 1C). In addition, we confirmed that GFP-tagged vPOIs (i.e. ORF3a, ORF6, ORF7, M) were merged with Flag-tagged vPOIs in co-expressed cells, indicating that tagging with GFP $(\sim 27$ $\mathrm{kDa}$ ) is acceptable for those vPOIs like as tagged with small epitope tag (Flag) (Figure S1B). These established were suitable for our further interactome study. 


\section{The GFP/GBP binding system is applicable for identifying the SARS-CoV-2 interactome in live cells}

As the POI-GFP and APEX2-GFP binding protein (GBP) system was previously validated for GFP-specific

electron microscope (EM) imaging (Ariotti et al., 2015), we utilized this GFP and GBP binding "plug and

play" system for the interactome analysis of vPOI-GFP by co-expression of TurboID-GBP via Spot-TurboID

workflow (Figure 2A). To confirm a specific binding between vPOI-GFP and TurboID-GBP, M, N, ORF3a,

ORF6, and ORF7b were selected. Confocal images of HEK293-AD cells co-expressing vPOI-GFP and

TurboID-GBP were identical to those of cells expressing vPOI-GFP alone (Figure 2B, S2), demonstrating

that GFP and GBP bound well, and the patterns of the biotinylated proteins merged with the GFP and GBP

patterns. Thus, we could confirm that co-expressed TurboID-GBP has a strong and specific binding interaction

with GFP-tagged vPOIs and it did not appear to interrupt the targeting of vPOI-GFP to specific organelles.

In the western blot analysis of proteins biotinylated by TurboID-GBP and detected using streptavidinhorseradish peroxidase (SA-HRP), we observed that the biotinylated protein patterns of TurboID-GBP were altered when it was co-expressed with GFP-tagged M, N, ORF3a, ORF3b, ORF6, ORF7a, ORF7b, ORF9b, ORF9c, or ORF10 proteins (Figure 2C, D, S3A-C). The change in SA-HRP western blot patterns of the biotinylated proteins by the PL enzyme (Lee et al., 2016) may reflect that the neighboring proteins around TurboID-GBP were significantly altered when TurboID-GBP was translocated to the co-expressed vPOI-GFP in the same cell. These experiments also showed that the GFP-tagged structural and accessory proteins of SARS-CoV-2 may be surrounded by different host proteins in cells, and that these proteins may be readily biotinylated by TurboID and identified using mass spectrometry via the Spot-TurboID workflow (Figure 2A).

\section{ORF3a and M SARS-CoV-2 proteins destructively perturb the ER membrane organization.}

Among the structural and accessory proteins that exhibit an ER targeting pattern, ORF3a and M contain 3

transmembrane (TM) domains (Figure 3A, B, S4A-B) and both proteins showed a similar alteration of protein

band patterns in western blot analysis, with a bigger molecular weight than expected (Figure 2D). ORF3a 
to possess pro-apoptotic activity (Ren et al., 2020). Similarly, M of SARS-CoV-2 shows $96.4 \%$ sequence similarity with M of SARS-CoV (Gordon et al., 2020), which was reported to target the ER, ER-Golgi intermediate compartment, and Golgi apparatus, and is associated with apoptosis (Chan et al., 2007) and nuclear factor-(NF) $\kappa \mathrm{B}$ signaling (Fang et al., 2007). We hypothesized that these proteins may perturb the ultrastructure of endomembrane systems, as it has been shown that many viral proteins target the endomembrane systems of host cells (Inoue and Tsai, 2013).

To test this hypothesis, we prepared ORF3a-APEX2 and M-APEX2 constructs, with APEX2 tagged to the C-terminus of the vPOIs (Figure 3A), and used them for EM imaging in HeLa cells following APEX-mediated diaminobenzidine (DAB) staining (Martell et al., 2012). ORF3a and M proteins largely disrupted the ER (Figure 3C, D; Figure S5A-B). ORF3a-APEX2 expression significantly increased cubic membrane (CM, also denoted as convoluted membrane) structure formation; moreover, these CM structures were generated in ORF3a-GFP expressing cells shown by CLEM imaging (Figure 3C, S5C). Notably, CM structures also form in coronavirus-infected cells (Deng and Angelova, 2021; Snijder et al., 2020), and they are considered as neoorganelles for the assembly of viral proteins (Uchil and Satchidanandam, 2003). Additionally, in ORF3a-GFP expressed HeLa cells, structure of double membrane vesicle (DMV, red arrows in Figure 3C) was discovered near ER and mitochondria. Formation of DMV by ORF3a-APEX2 was reproduced in A549 lung cell line (Figure 3E, G). We confirmed that these CM and DMV structures were not observed in SEC61B-APEX2 or APEX2 transfected controls (Figure S6A-C). Since DMV formation is believed to house replication complexes of various RNA viruses (Cortese et al., 2020; Klein et al., 2020; Wolff et al., 2020), our result indicates that ORF3a of SARS-CoV-2 plays an important role in the formation of ER-derived neo-organelles (i.e. CM and DMV) that are essential for viral replication in host cells.

Similarly, ER was clearly disrupted in M-expressing cells (Figure 3D) and appeared to curl into whorl patterns (also termed as aggresomes). These patterns were also observed in herpes simplex virus-infected cells (Nii et al., 1968) and ER stress-induced cells (Schuck et al., 2014; Snapp et al., 2003). In CLEM imaging of M-GFP (Figure S5D), we observed the formation of multilamellar bodies (MLB) at the ER membrane (Figure 3D, F) and electron-dense autophagic vesicles (green arrows in Figure S5D). The biogenesis of MLB regulated is by autophagy (Hariri et al., 2000) and MLBs are utilized during extracellular vesicle-type viral 
egress (Bunyavirus) (Sanz-Sánchez and Risco, 2013). In flavivirus replication (such as Zika virus), autophagy

is usually activated and autophagic vesicles accumulate inside the cells in in cellulo (Hamel et al., 2015) and in vivo (Cao et al., 2017) experiments. In our study, these structures were not detected in non-transfected HeLa (Figure S5B) and A549 cell controls (Figure S6A). Moreover, we confirmed that the structure of ER, Golgi, and mitochondria did not change in SEC61B-APEX2 or APEX2-expressed cells (Figure S6B-C). Our EM results therefore imply that the ORF3a and $\mathrm{M}$ proteins of SARS-CoV-2 may largely contribute to the generation of ER-derived neo-organelles (Fernández de Castro et al., 2014; Tenorio et al., 2018; Xie et al., 2019) for efficient viral assembly and replication by remodeling the endomembrane systems of host cells. To identify the host proteins involved in this process, we conducted an in cellulo interactome analysis of the SARS-CoV-2 ORF3a and M proteins using GFP-tagged constructs with TurboID-GBP via the Spot-TurboID workflow.

\section{ORF3a and $M$ interactomes showed perturbed proteomic landscape at the ER membrane.}

For mass spectrometric analysis, we used the aforementioned Spot-TurboID method (Figure 2A) to obtain an accurate interactome map of the ORF3a and M proteins. To obtain the biotinylated peptidome, HEK293T cells co-expressing vPOI-GFP and TurboID-GBP and control HEK293T cells co-expressing GFP and TurboID-GBP (Figure 4A) were treated with biotin $(50 \mu \mathrm{M}, 30 \mathrm{~min})$ in full 10\% fetal bovine serum medium, washed with cold Dulbecco's phosphate-buffered saline, and lysed using $2 \%$ sodium dodecyl sulfate in $1 \times$ Tris-buffered saline. Lysate samples were trypsin-digested prior to SA-bead enrichment for biotinylated peptidome enrichment. Biotinylated peptides were isolated from the SA-beads and injected to the Orbitrap Fusion Lumos mass spectrometer. A total of 4232, 3818, and 6299 peptide-spectrum matches containing biotin-moiety peptides at the lysine residue $(\mathrm{K}+226)$ were detected in the ORF3a-GFP + TurboID-GBP, MGFP + TurboID-GBP, and unconjugated GFP (control) + TurboID-GBP expressing cells, respectively.

Based on the reproducibility and similarity values of the biotinylated peptidome of each sample (Lee et al., 2016), replicate samples under the same conditions were clustered together, confirming the reproducibility of the experiment (similarity value $>0.84$, Figure S7A-D). From the volcano plot analysis of mass signal intensity of proteins biotinylated by TurboID-GBP, proteins that were more strongly biotinylated in the 
ORF3a-GFP and M-GFP co-expressed samples versus the control GFP-expressed sample were selected as interactome proteins of ORF3a and $\mathrm{M}$, respectively $\left(\log _{2}\right.$ (fold change, FC) $\geq 2.3$ and $-\log _{10} \mathrm{p}$-value $\geq 2.3$,

Figure 4B, S7E). The major population of the interactomes for ORF3a and M comprises endomembrane system proteins, suggesting that SARS-CoV-2 ORF3a and M are primarily localized at the ER.

Among the 117 filtered proteins for the ORF3a interactome, $40.2 \%$ were located at the plasma membrane and 37.6\% were located at the endomembrane (Figure 4C, S7F). Among the 191 filtered proteins of the $M$ interactome, $49.7 \%$ were located at the plasma membrane and $25.1 \%$ were located at the endomembrane (Figure 4C, S7F). Thus, a large proportion of plasma membrane and endomembrane proteins were present in both, the ORF3a and M interactomes. According to gene ontology analysis, proteins associated with regulation of localization and ubiquitin-dependent ER-associated protein degradation (ERAD) pathway were highly enriched among the 117 proteins of the ORF3a interactome (Figure 4D, S7G). Proteins related to localization and nitrogen compound transport were highly enriched among the 191 proteins comprising the M interactome (Figure 4D, S7G). From these analyses, we could see that the molecular functions of ORF3a and M are highly related to localization and transport of other substances within the endomembrane of host cells.

To further our understanding of these interactions, we then filtered the top 30 most strongly biotinylated proteins (red or blue-colored dots in Figure 4B) among the ORF3a and M interactomes, respectively. The 30 filtered proteins of the ORF3a interactome were classified according to localization and function (Figure 4E). Surprisingly, 13 of these 30 proteins (43.3\%) overlapped with the recently identified mitochondrial-associated membrane (MAM) proteome determined using Contact-ID (Kwak et al., 2020). This suggests that ORF3a of SARS-CoV-2 is localized at the MAM, in line with a previous host interactome analysis of SARS-CoV-2 using the Co-IP method (Davies et al., 2020). Since the MAM-enriched ORF3a interactome proteins are associated with vesicle transport (BET1, BET1L, SAR1A, and VAMP3), regulation of membrane integrity (EPHA2, JAM3, and SEC63), and lipid synthesis and steroid binding/processes (DHCR7 and SCD5), we postulated that ORF3a may be involved in the regulation of vesicle trafficking at the MAM to support viral assembly and egress processes similar to other viral proteins that target the MAM, such as the NS5A and NS5B proteins in hepatitis C virus (Hamamoto et al., 2005). Moreover, several ion transport proteins that are part of the endomembrane system (such as CLCC1, SCD, SLC16A1, SLC22A5, TMEM110, and TMEM165) 
were identified in the ORF3a interactome. Based on previous findings that ORF3a of SARS-CoV regulates the ion channels at the ER membrane (Chan et al., 2009; Issa et al., 2020) and ORF3a of SARS-CoV-2 forms $\mathrm{Ca}^{2+}$ and $\mathrm{K}^{+}$channels (Kern et al., 2020), we postulate that ORF3a may localize at the sub-domain of ER where ion transport proteins cluster.

Similarly, the top 30 filtered proteins of the $\mathrm{M}$ interactome were classified by localization and molecular function (Figure 4F). Among these proteins, we found the proteins associated with cell cycle/apoptosis (ITGB1, IRS4, WDR6, and STEAP3) to be highly enriched in our M interactome. We also observed that several vesicle transport proteins (BET1L, SAR1A, VAMP3, and YKT6) were highly enriched in the M interactome, which may influence ER vacuolization and apoptosis associated with the M protein (Chan et al., 2007) (Figure 3D, F).

Moreover, several known viral interacting host proteins, such as CXADR and ZC3HAV1, were found in the $\mathrm{M}$ interactome. Interestingly, infection of SARS-CoV-2 induced an increase in the transcript level of CXADR (coxsackievirus and adenovirus receptor) (Dörner et al., 2004; Martino et al., 2000) in a SARS-CoV2 infected patient sample (Zhou et al., 2020). Among our M interactome proteins, ZC3HAV1 (CCCH-type zinc-finger antiviral protein) inhibits viral replication by recruiting other proteins responsible for sensing numerous viral RNAs (Kerns et al., 2008; Oshiumi et al., 2015), including human immunodeficiency virus(HIV)-1 (Zhu et al., 2011), Moloney and murine leukemia virus (Lee et al., 2013), and xenotropic MuLVrelated virus (Wang et al., 2012b). Notably, ZC3HAV1 was also enriched in the ORF3a interactome. Thus, our data suggest that ZC3HAV1 is also involved in the anti-viral response against SARS-CoV-2.

\section{Spot-TurboID reveals topology of TM proteins interacting with ORF3a and M}

Since ORF3a and M are targeted to ER membrane (Figure S1A), it is reasonable that majority of their interacting proteins are membrane residents such as endomembrane proteins or plasma membrane proteins, synthesized at the ER membrane: ORF3a: 78\%, M: 75\% (Figure 4C). For membrane proteins, identification of their membrane topologies is crucial to understanding their domain-wise function at either side of the membrane. In our work, membrane topological information of the biotin-labeled membrane proteins was easily extracted. Using our Spot-TurboID method, we obtained mass spectrometry data that included the 
biotinylation sites of each digested peptides. All digested peptides isolated following SA-bead enrichment had at least one biotin-modified site at a lysine (K) residue. Since the biotinylation by TurboID-GBP occurred via cytosolic regions of the protein, biotinylated sites on proximal interacting proteins of vPOI-GFP logically faced the cytosol. We then obtained membrane topological information for proteins harboring a TM domain using mass spectrometry data. It is noteworthy that using similar approaches, we successfully revealed the topologies of inner mitochondrial membrane (Lee et al., 2016) and MAM proteins (Kwak et al., 2020).

Using this workflow, $22 \mathrm{TM}$ proteins were identified in each of the ORF3a and M interactomes and the biotinylation sites and topology of these proteins are shown in the figures (Figure 5, S8A-B). For example, the biotinylation sites of SEC61B and VAMP3 (K20 of SEC61B, K35 of VAMP3) from the ORF3a interactome are well matched to previously characterized topologies. Based on these results confirming the reliability of the Spot-TurboID data, we propose the hitherto unknown topologies of multiple ORF3a and M interacting membrane proteins (CLCC1, DHCR7, TMEM110, FKBP8, RNF5, UBR3, and UBIAD1) (yellowcolored proteins in Figure 5).

It is noteworthy that this detailed topological information can be only obtained by direct detection of biotinylated peptides, however, conventional methods that overlook these biotin-PTM signatures cannot report it. We believe that our data provide detailed information on the domains heading toward cytosolic domain of ORF3a and M proteins at the membrane, which lays foundation for further studies on host membrane proteins. Notably, among the biotinylated membrane proteins, several lysosome-associated proteins (i.e., VPS16, VMA21, ITM2C, TMEM165, and RAB7A) were identified in the ORF3a interactome. This finding is consistent with recent reports that ORF3a hijacks the HOPS complex and RAB7, which are necessary for membrane contact between autophagosomes and lysosomes for autolysosome formation (Miao et al., 2021; Zhang et al., 2021). Our result implies that ORF3a may dynamically localize from the MAM to the autophagosome and autolysosome because autophagosome formation is also known to be initiated at the MAM (Hamasaki et al., 2013).

\section{RNF5 ubiquitinylate ORF3a of SARS-CoV-2}

In regard to the ORF3a interaction with membrane proteins at the autophagosome and lysosome, RNF5, which 
is strongly biotinylated by Spot-TurboID (Figure 6A), interests us because it is an ER-anchored E3 ubiquitin-

protein ligase involved in regulating the autophagic process during bacterial infections (Kuang et al., 2012).

Interestingly, RNF5 is involved in the inflammatory response (Li et al., 2019), and it regulates the antiviral

response by degrading an outer mitochondrial protein, MAVS (Zhong et al., 2009; Zhong et al., 2010), which implies that RNF5 might function at the MAM. Indeed, RNF5 was identified as an MAM-resident E3 ubiquitin ligase in our recent study (Kwak et al., 2020).

Since the molecular function of RNF5 with SARS-CoV-2 is not fully characterized yet, we conducted further studies to reveal its functional relationship with SARS-CoV-2 proteins. From confocal microscopy experiments, we observed that cytoplasmic dispersed Flag-conjugated RNF5 was largely altered by ORF3a and $\mathrm{M}$ expression and co-localized with the respective viral proteins (Figure 6B-C, S9A). This result indicates that RNF5 might be activated by ORF3a and M protein expression. From western blot analysis after Co-IP, we observed that overexpression of RNF5 induced further ubiquitination of ORF3a protein (Figure 6D, S9DE). It is noteworthy that overexpression of a mutant RNF5(C42S) whose ubiquitin-transferring ring finger domain is not functional owing to C42S mutation (Zhong et al., 2009) did not induce ubiquitination of ORF3a (Figure S10). These results indicate that RNF5 is involved in the ubiquitination of viral proteins and their interacting host proteins (Figure 6E).

In our study, results of western blot analysis revealed increased expression of ORF3a and M following MG132 treatment (Figure S9B-C). Thus, we propose that RNF5 is responsible for ubiquitination and degradation of ORF3a and M proteins derived from SARS-CoV-2. Our result is in a good agreement with a recent study that selected RNF5 as a specific ubiquitin ligase for viral proteins of SARS-CoV-2 from genomewide screening (Zhen Yuan, 2021). Together with our result, we expect RNF5 to be an effective target for the development of anti-viral therapeutics for SARS-CoV-2.

\section{SARS-CoV-2 ORF3a influences ER-mitochondria contact sites and the secreted proteins of host cells}

Interestingly, we also observed that many of the ORF3a and M interactome proteins overlapped with our recently identified MAM proteins. We have identified 115 local resident proteins using Contact-ID, which utilized the reconstituted biotinylating activity of split BioID fragments at the MAM, which is an ER and 
mitochondrial contact site (Kwak et al., 2020). Twenty-eight of the proteins that filtered out from the ORF3a interactome (23.9\%) and the 24 from the $\mathrm{M}$ interactome (12.6\%), overlapped with the 115 proteins previously identified to be a part of the MAM proteome. A total of 18 proteins overlapped between ORF3a, M, and the MAM proteome (Figure 7A). The complete list of proteins in the ORF3a and M proteomes that overlap with the MAM proteome, classified by function, are given in Figures $\mathbf{7 B}$ and $\mathbf{7 C}$, respectively. Since many of the ORF3a interactome proteins overlapped with those from the MAM proteome rather than the M interactome, we questioned whether ORF3a could more strongly hinder MAM formation.

To address this, we used the Contact-ID tool to monitor changes in the proteomic composition at the MAM in response to ORF3a expression (Figure 7D). (Contact-ID generated more biotinylated proteins in the ORF3a-expressing sample compared to that in the control sample (blue arrows in Figure 7E; Figure S11AD), which implies that ORF3a may lead to a considerable change of the proteomic landscape at the MAM. We also found that ORF3a was biotinylated by Contact-ID (red arrows in Figure 7E). Thus, we are currently conducting further investigations to analyze which proteins are recruited to the MAM in response to ORF3a expression. Similar to ORF3a, we observed that M was also biotinylated by Contact-ID (Figure S12).

We speculate that the expression of vPOI may change the secretory proteome because our EM results showed that ORF3a and M largely perturb the endomembrane system and many viral infections have been known to affect secretory proteome profiles (Lietzén et al., 2019). To investigate alterations in the host cell secretome, we used recently developed method dubbed iSLET (in situ secretory protein labeling via ERanchored TurboID) (Kim et al., 2020). In the iSLET method, SEC61B-TurboID is utilized to biotinylate secreted proteins at the ER luminal side near to the SEC61 translocon channel since most secreted proteins transit through the ER lumen via the SEC61B translocon channel. Secretory proteins biotinylated in SEC61BTurboID-expressing cells can be detected in the culture media or mouse bloodstream. In this study, we utilized the iSLET method to assess whether the secretome profiles of the host cells changed in response to ORF3a and $\mathrm{M}$ expression (Figure 7F).

In the SA-HRP western blot results, the amounts of biotinylated proteins in the culture media of cells coexpressing SEC61B-TurboID and ORF3a were substantially higher compared to that of the control sample lacking ORF3a expression (Figure 7G, S13A-B). In addition, we found ORF3a in the culture media of the 
cells (red arrows in Figure 7H, S13C). In whole cell lysates, ORF3a was also biotinylated by SEC61B-

TurboID (Figure S14). Similar to ORF3a, we observed that the amounts of biotinylated proteins increased in the secretome of M-expressed cells (Figure S15A), and M protein was also secreted from cells (Figure S15B) and was biotinylated by SEC61B-TurboID (Figure S15C).

These results imply that ORF3a and M may upregulate cargo secretion from the ER and there may be a specific sorting pathway for the secretion of ORF3a in the ER lumen, as has been shown for other secreted viral proteins (Alefantis et al., 2005). In the ORF3a interactome, SAR1A/B and USE1 are known to play essential roles in cargo secretion at the ER-Golgi interface (Petrosyan et al., 2015) and further investigation is required to identify whether the interaction of these vesicle transport proteins with ORF3a could induce ERderived vesicle formation and changes in the secretome profile.

\section{Discussion}

In this study, we demonstrated that ORF3a and M perturb the integrity of endomembrane systems in host cells, thereby resulting in devastating effects. As shown in other viruses (Dengue, porcine epidemic diarrhea, and Zika viruses) that utilize the ER for replication (Lee et al., 2018; Monel et al., 2017; Wang et al., 2012a; Zou et al., 2019), including SARS-CoV (Fung et al., 2014), our data show that ORF3a and M of SARS-CoV2 largely affect membrane integrity and the proteomic landscape at the ER. Although we employed ectopic expression method of ORF3a and M protein constructs to ensure biosafety, a recent study shows that ectopic expression of ORF3a of SARS-CoV-2 is enough to show pathogenesis of SARS-CoV-2 in Drosophila (Shuo Yang, 2020). Since some of the proteins we identified, including RNF5, are also highlighted as viral host proteins in other studies of SARS-CoV-2 (Zhen Yuan, 2021), we believe that our interactome data reflects physiological networks of the ORF3a and M proteins of SARS-CoV-2.

During our interactome analyses of ORF3a and M, we observed a notable overlap with the MAM proteome (Kwak et al., 2020). Among the overlaps, VAP-A and VAP-B interact with NS5A and NS5B to promote viral replication and protein assembly of hepatitis C virus at the MAM (Hamamoto et al., 2005). We confirmed that RNF5 (Kuang et al., 2012), co-localized with ORF3a and induced ubiquitination of ORF3a (Figure 6). This result is consistent with previous studies that showed ubiquitination of SARS-CoV-2 ORF3a (Cao et al., 2021) 
and RNF5-induced ubiquitination of SARS-CoV-2 M (Zhen Yuan, 2021). Whether overexpression or chemical activation of RNF5 could be used as a novel anti-viral or anti-inflammatory strategy for SARS-CoV-2 warrants further investigations.

In our study, RNF5 was identified as part of the ORF3a interactome, whereas previously reported interactome mapping approaches such as conventional proximity labeling technique (Samavarchi-Tehrani et al., 2020) and affinity-purification method (Gordon et al., 2020) could not identify RNF5 in the ORF3a interactome although their selections contain comparable or more numbers of findings in the list. Thus, our Spot-TurboID method is superior to previous methods for identifying proteins of interest in an interactome.

Since MAM is a cholesterol-enriched intracellular lipid raft (Area-Gomez et al., 2012), several proteins associated with lipid metabolism and transport are observed at this domain (Kwak et al., 2020). Notably, among 119 proteins identified in ORF3a interactome in this study, 34 proteins were earlier characterized as lipid binding proteins (LBP) (Niphakis et al., 2015) and 15 proteins were reported at the MAM (Kwak et al., 2020) (Dataset S1). Thus, we speculate that ORF3a forms neo-organelles (i.e. CM and DMV) by altering ultrastructure and lipid contents of MAM since dynamic lipid transport at the MAM (Phillips and Voeltz, 2016) can supply lipid molecules for the formation of autophagosomal membrane formations (Hamasaki et al., 2013). Since several lysosome-associated membrane proteins (e.g. VPS16, RAB7A) are observed in our ORF3a interactome as also observed in other ORF3a interactome list using affinity purification method (Stukalov et al., 2021), consistent with recent reports that ORF3a is localized at the late endosome and lysosome (Miao et al., 2021; Zhang et al., 2021), we postulated that these ORF3a-associated vesicles (e.g., CM and DMV) might be interconnect or fused with the lysosome at some points.

Additionally, MAM is a site of active calcium transport from the ER to the mitochondria; a recent study characterized ORF3a of SARS-CoV-2 as $\mathrm{Ca}^{2+}$ and $\mathrm{K}^{+}$channels. Thus, we postulate that ORF3a may derange the calcium transport, which in turn, can negatively impact MAM function. Since abnormal MAM formations correlate with various metabolic diseases such as type 2 diabetes (Tubbs et al., 2018) and neurodegenerative diseases, including Alzheimer's disease, Parkinson's disease, amyotrophic lateral sclerosis (Schon and Przedborski, 2011), and Wolfram syndrome (Delprat et al., 2018), further studies might be required to monitor the possible progression of these MAM-related metabolic diseases in SARS-CoV-2-infected patients (Rahman 
397 et al., 2020).

398 In addition, we also found that many of the proteins in the ORF3a and M interactomes are targeted by 399 approved drug molecules, which may be useful for drug repurposing therapeutic strategies. The druggable 400 proteins targeted by previously approved drug molecules are listed in Supplementary Table 2-3.

401 In this study, we also provide evidence that our Spot-TurboID workflow using the GFP/GBP binding system 402 (vPOI-GFP/TurboID-GBP) is effective for interactome mapping of viral proteins in live cells. Since several 403 viral proteins are initially cloned with GFP for the imaging experiments typically performed in the initial 404 stages of many virus studies, we expect that our TurboID-GBP could be an effective "plug-and-playable" 405 component for rapid host interactome analysis with various GFP-tagged viral proteins, without cloning 406 additional constructs for PL experiments. This is especially relevant in situations where time is a constraint, 407 such as that in the current COVID-19 pandemic. 
bioRxiv preprint doi: https://doi.org/10.1101/2021.06.01.446555; this version posted June 1,2021 . The copyright holder for this preprint (which was not certified by peer review) is the author/funder, who has granted bioRxiv a license to display the preprint in perpetuity. It is made available under aCC-BY-NC 4.0 International license.

\section{Resource Availability \\ Lead Contact}

Further information and request of reagents or resources should be directed Contact, Dr. Rhee H. W. (rheehw@snu.ac.kr)

\section{Materials Availability}

Upon reasonable requests, unique reagents utilized in this paper could be provided.

\section{Data and Code Availability}

The raw LC-MS data generated from this study have been deposited on ProteomeXchange Consortium (accession no. PDX022355, User name: reviewer_pxd022355@ebi.ac.uk, Password: jvuXMLgS).

\section{Materials}

\begin{tabular}{|c|c|c|}
\hline REAGENT or RESOURCE & SOURCE & IDENTIFIER \\
\hline \multicolumn{3}{|l|}{ Antibodies } \\
\hline V5 Tag Monoclonal Antibody (mouse) & Invitrogen & \#R960-25 \\
\hline GFP Monoclonal Antibody (mouse) & Invitrogen & \#MA5-15256 \\
\hline $\begin{array}{l}\text { Anti-StrepMAB-Classic, purified, lyophilized, ( } \\
\text { mouse) }\end{array}$ & IBA & \#2-1597-001 \\
\hline HA Tag Polyclonal Antibody & Thermofisher & $\# 71-5500$ \\
\hline FLAG rabbit Polyclonal Antibody & Sigma aldrich & \#F7425 \\
\hline Ubiquitin Antibody & $\begin{array}{l}\text { Santa Cruz biotech } \\
\text { nology }\end{array}$ & \#SC-166553 \\
\hline Alexa Fluor 568 IgG mouse & Molecular probes & \#A11004 \\
\hline Streptavidin, Alexa Fluor 647 conjugate & Invitrogen & \#S21374 \\
\hline Goat Anti-Mouse IgG $(\mathrm{H}+\mathrm{L})$-HRP conjugate & Bio-rad & $\# 1706516$ \\
\hline Anti-rabbit IgG, HRP-linked Antibody & Cell signaling & \#7074S \\
\hline Streptavidin-HRP & Thermofisher & $\# 21126$ \\
\hline Anti-Flag affinity gel beads & Bimaker & \#B23102 \\
\hline $4 \%$ paraformaldehyde & CHEMBIO & \#CBPF-9004 \\
\hline $\begin{array}{l}\text { HyClone Dulbecco's Modified Eagle Medium } \\
\text { (DMEM) with high glucose: Liquid }\end{array}$ & Cytiva & \#SH30022.01 \\
\hline FBS & Atlas Biologicals & \#EF-0500-A \\
\hline biotin & Alfa aesar & \#A14207 \\
\hline doxycycline & Sigma aldrich & \\
\hline RIPA lysis buffer & ELPISBIO & \#EBA-1149 \\
\hline Protease inhibitor cocktail & Invitrogen & \#78438 \\
\hline \multicolumn{3}{|l|}{ Reagent for mass preparation } \\
\hline Sodium azide & Alfa aesar & \#14314 \\
\hline Sodium ascorbate & Sigma aldrich & \#A4034 \\
\hline Trolox & Sigma aldrich & \#238813 \\
\hline Urea & Sigma aldrich & \#U5378 \\
\hline $20 \mathrm{X}$ TBS & Thermofisher & $\# 28358$ \\
\hline Acetone & Sigma aldrich & $\# 650501$ \\
\hline Ammonium bicarbonate & Sigma aldrich & \#A6141 \\
\hline Sodium dodecyl sulfate & Sigma aldrich & $\# 436143$ \\
\hline TPCK-Trypsin & Thermofisher & \#20233 \\
\hline Dithiothreitol & Sigma aldrich & $\# 43819$ \\
\hline Iodoacetoamide & Sigma aldrich & \#I1149 \\
\hline Trifluoroacetic acid & Sigma aldrich & \#T6508-10AMP \\
\hline Formic acid & Thermofisher & $\# 28905$ \\
\hline
\end{tabular}


bioRxiv preprint doi: https://doi.org/10.1101/2021.06.01.446555; this version posted June 1 , 2021. The copyright holder for this preprint (which was not certified by peer review) is the author/funder, who has granted bioRxiv a license to display the preprint in perpetuity. It is made available under aCC-BY-NC 4.0 International license.

\begin{tabular}{|l|l|l|}
\hline Streptavidin-coated magnetic beads & Pierce & $\# 88817$ \\
\hline Equipment & & \\
\hline Speed-vac & & \\
\hline Thermomixer & & \\
\hline
\end{tabular}

\section{Methods \\ Cell lines}

HEK293 cells and HEK293T cells were gift from Professor Kim, H. at Ulsan National Institute of Science and Technology (Korea). SEC61B-V5-TurboID stably expressed HEK293 Flip-in T-rex cells were from the past paper. HeLa cells and A549 cells were from Laboratory of Dr. Mun at Korea Brain Research Institute (Korea). Cell lines were cultured according to the manufacturer's instructions.

\section{Expression Plasmids}

Genes with epitope tag (i.e. V5, FLAG, HA, twin strep) were cloned into pCDNA3, pCDNA3.1, and pCDNA5 using digestion with enzymatic restriction sites and ligation with T4 DNA ligase. After digesting PCR products and cut vectors simultaneously, they were ligated. CMV promoter made genes expressed possible in mammalian cells. Table S1 summarized constructs information. Templates of SARS-CoV-2 were obtained from Professor Kim, Ho Min (KAIST) and Professor Kim, V. Narry (SNU).

\section{Cell Culture and Transfections}

Cell lines were examined for morphology and confluence using a microscope. Cells were incubated with in Dulbecco's Modified Eagle Medium (Cytiva, cat. No., SH30022.01) supplemented with 10\% fetal bovine serum (Atlas biologicals, cat. No., EF-0500-A) in a $37{ }^{\circ} \mathrm{C}$ incubator $5 \% \mathrm{CO}_{2}(\mathrm{v} / \mathrm{v})$. Genes were introduced into cells using PEI, when $60-80 \%$ cell confluence.

\section{Stable Expression of SEC61B-V5-TurboID Cell Line (Flip-in HEK293T-Rex)}

SEC61B-V5-TurboID expression was induced by treatment of $5 \mathrm{ng} / \mathrm{mL}$ doxycycline (Sigma Aldrich). For transient expression of other constructs, transfection using PEI could do the same time with treatment of doxycycline.

\section{Biotin Labeling in Live Cells}

Using transient transfection reagent, PEI, genes including TurboID or BioID were introduced into HEK293AD, HEK293 or HEK293T cells. After 16-24 h, the medium was changed to $500 \mu \mathrm{L}$ (for 24 well plate) or 1 $\mathrm{mL}$ (for 12 well plate) of fresh growth medium containing $50 \mu \mathrm{M}$ biotin (Alfa aesar, cat. No. A14207). These cells were incubated at $37^{\circ} \mathrm{C}$ and $5 \% \mathrm{CO}_{2}$ for $30 \mathrm{~min}$ for using TurboID (or $16 \mathrm{~h}$ for using split BioID) in accordance with the previously published protocols. Next, the reaction was stopped by washing, two times, with Dulbecco's phosphate-buffered saline (DPBS). After, lysis was followed for western blot analysis or mass sampling, or fixation was followed for fluorescence microscope imaging.

Using transient transfection reagent, PEI, genes including APEX2 were introduced into HEK293-AD, HEK293 or HEK293T cells. After 16-24 h, the medium was changed to $500 \mu \mathrm{L}$ (for 24 well plate) or $1 \mathrm{~mL}$ (for 12 well plate) of fresh growth medium containing $250 \mu \mathrm{M}$ desthiobiotin-phenol. These cells were incubated at $37{ }^{\circ} \mathrm{C}$ and $5 \% \mathrm{CO}_{2}$ for $30 \mathrm{~min}$ in accordance with the previously published protocols (Lee et al., 2017). $\mathrm{H}_{2} \mathrm{O}_{2}$ (1 mM; Sigma Aldrich, cat. No., STBJ2658) was added to each well for 1 min at room temperature. Next, this reaction was terminated by washing, two times, with Dulbecco's phosphate-buffered saline (DPBS) containing $5 \mathrm{mM}$ Trolox (Sigma Aldrich, cat. No., 238813-25G), $10 \mathrm{mM}$ sodium azide (Alfa Aesar, cat. No., N07E043), and $10 \mathrm{mM}$ sodium ascorbate (Sigma Aldrich, cat. No., A4034-100G). After, lysis was followed for western blot analysis or mass sampling, or fixation was followed for fluorescence microscope imaging.

\section{Fluorescence Microscope Imaging}

Cells were split on the coverslips (thickness no. 1.5 and radium: $18 \mathrm{~mm}$ ) for microscope imaging.vPOI-GFP expressed cells were fixed using 4\% paraformaldehyde solution (CHEMBIO, cat. No. CBPF-9004) at room temperature for 10-15 min. Cells were then washed with Dulbecco's phosphate-buffered saline (DPBS) two 
times. To detect vPOI-GFP expression, washed cells were maintained in DPBS on $4{ }^{\circ} \mathrm{C}$ refrigerator for imaging by Leica (NICEM in Seoul National University, Korea) with objective lens (HC PL APO 100x/1.40 OIL), White Light Laser (WLL, 470-670 nm, $1 \mathrm{~nm}$ tunable laser), HyD detector and controlled by LAS X software.

Co-expressed or biotin-labeled cells were fixed with 4\% paraformaldehyde solution (CHEMBIO, cat. No. CBPF-9004) in DPBS at room temperature for 10-15 min. Cells were then washed with DPBS, two times, and permeabilized with cold methanol at $-20^{\circ} \mathrm{C}$ for $10 \mathrm{~min}$. Cells were washed again, two times, with DPBS and blocked for $30 \mathrm{~min}$ with $2 \% \mathrm{BSA}$ in DPBS at room temperature $\left(25^{\circ} \mathrm{C}\right)$. To detect expression pattern or biotinylation pattern, the primary antibody, such as anti-V5 (Invitrogen, cat. No. R960-25, 1:5,000 dilution), was incubated for $1 \mathrm{~h}$ at room temperature. After washing two times with TBST, cells were simultaneously incubated with secondary Alexa Fluor 568 IgG mouse (Molecular probes, cat. No. A11004, 1:1,000 dilution) and Streptavidin, Alexa Fluor 647 conjugate (Invitrogen, cat. No. S21374, 1:1,000 dilution) for 30 min at room temperature. Cells were then washed two times with TBST and maintained in DPBS at $4{ }^{\circ} \mathrm{C}$ for imaging using Leica (NICEM in Seoul National University, Korea). Pearson correlation was conducted using image J software program $(\mathrm{NIH})$.

\section{Co-immunoprecipitation}

Constructs were transfected using PEI. After more than $16 \mathrm{~h}$, samples were lysed using RIPA buffer (ELPISBIO, cat. No. EBA-1149) including $1 \times$ protease inhibitor cocktail (Invitrogen, cat. No. 78438) for 10 min at room temperature. After transferring these lysates to e-tube, samples were vortexed for 2-3 min at room temperature. After centrifugation at $15,000 \times \mathrm{g}$ for $10 \mathrm{~min}$ at $4{ }^{\circ} \mathrm{C}$, supernatant was collected. These samples were incubated with already washed Anti-Flag affinity gel beads (Bimaker, cat. No.B23102) for $2 \mathrm{~h}$ at $4{ }^{\circ} \mathrm{C}$. Then they were washed more than three times and eluted using $1 \times$ SDS-PAGE loading buffer at $95{ }^{\circ} \mathrm{C}$ for 5 min.

\section{Obtaining Secreted Proteins in Cell Culture Media}

After biotin labeling of HEK293 cells expressing SEC61B-TurboID, cells were incubated with no FBS DMEM for $16 \mathrm{~h}$. After collecting these cell culture media in $15 \mathrm{~mL}$ tube, these samples were concentrated using amicon filter (Millipore, cat. No. UFC501096) at $12,000 \times g$ at $4{ }^{\circ} \mathrm{C}$ for $20 \mathrm{~min}$. Concentrated proteins were collected using $8 \mathrm{M}$ urea (Sigma Aldrich, cat. No. U5378). These samples were used for immunoblotting.

\section{Immunoblotting}

Transfected and biotinylated cell samples were lysed using RIPA buffer (ELPISBIO, cat. No. EBA-1149) including $1 \times$ protease inhibitor cocktail (Invitrogen, cat. No. 78438) for $10 \mathrm{~min}$ at room temperature. After transferring these lysates to e-tube, samples were vortexed for 2-3 $\mathrm{min}$ at room temperature. Using centrifugation at $15,000 \times \mathrm{g}$ for $10 \mathrm{~min}$ at $4{ }^{\circ} \mathrm{C}$, samples were clarified. They were boiled with $1 \times$ SDS-PAGE loading buffer at $95{ }^{\circ} \mathrm{C}$ for $5 \mathrm{~min}$. After resolving protein samples using SDS-PAGE and transferring protein samples to membrane, immunoblotting analysis was performed using antibodies. Membranes were blocked for 30 min with $2 \%$ skim milk solution at room temperature. After washing three times with TBST for 5 min each, at room temperature, primary antibodies, namely anti-V5 (Invitrogen, cat. No. R960-25, 1:10,000 dilution), anti-GFP (Invitrogen, cat. No. MA5-15256, 1:3,000 dilution), anti-HA (Thermofisher, cat. No. 715500, 1:10,000 dilution), anti-FLAG (Sigma Aldrich, cat. No. F7425, 1:10,000 dilution), and anti-strep (IBA, cat. No. 2-1597-001, 1:1,000 dilution), was incubated for $16 \mathrm{~h}$ at $4{ }^{\circ} \mathrm{C}$. After washing three times with TBST for $5 \mathrm{~min}$ at room temperature, secondary antibodies, namely mouse-HRP (Bio-rad, cat. No. 1706516, 1:3,000 dilution) and rabbit-HRP (Cell signaling, cat. No. 7074S, 1:3,000 dilution), or SA-HRP (Thermofisher, cat. No. 21126, 1:10,000 dilution) were incubated for $1 \mathrm{~h}$ at room temperature. After washing three times with TBST for $5 \mathrm{~min}$ at room temperature, results of immunoblotting assay were obtained using ECL solution using GENESYS program. Line scan analysis was performed using image J software program (NIH). After subtraction of intensity value at background, protein bands from top to bottom of each lane were putted as Xaxis and intensity of bands from top to bottom of each lane was putted as y-axis.

\section{EM imaging and CLEM}

To observe the DAB-stained cells, cells were cultured in 35-mm glass grid-bottomed culture dishes (MatTek 
bioRxiv preprint doi: https://doi.org/10.1101/2021.06.01.446555; this version posted June 1,2021 . The copyright holder for this preprint (which was not certified by peer review) is the author/funder, who has granted bioRxiv a license to display the preprint in perpetuity. It is made available under aCC-BY-NC 4.0 International license.

life sciences, MA, USA) to $30-40 \%$ confluency. Then cells were transfected with DNA plasmids using Lipofectamin 2000 (Life Technologies, Carlsbad, CA, USA). Next day, cells were fixed with $1 \%$ glutaraldehyde (Electron Microscopy Sciences, cat. No. 16200) and 1\% paraformaldehyde (Electron Microscopy Sciences, cat. No. 19210) in $0.1 \mathrm{M}$ cacodylate solution (pH 7.0) for $1 \mathrm{~h}$ at $4{ }^{\circ} \mathrm{C}$. After washing, $20 \mathrm{mM}$ glycine solution was used for quench unreacted aldehyde. DAB staining (DAB, Sigma, cat. No. D8001) took approximately $20-40$ min until a light brown stain was visible under an inverted light microscope. DAB stained cells were post-fixed with $2 \%$ osmium tetroxide in distilled water for 30 min at $4{ }^{\circ} \mathrm{C}$ and en bloc in $1 \%$ uranyl acetate (EMS, USA, cat. No. 22400) overnight and dehydrated with a graded ethanol series. The samples were then embedded with an EMBed-812 embedding kit (Electron Microscopy Sciences, USA, cat. No. 14120) and polymerized in oven at $60{ }^{\circ} \mathrm{C}$. The polymerized samples were sectioned $(60 \mathrm{~nm})$ with an ultramicrotome (UC7; Leica Microsystems, Germany), and the sections were mounted on copper slot grids with a specimen support film. Sections were stained with uranyless (Electron Microscopy Sciences, cat. No. 22409) and lead citrate (Electron Microscopy Sciences, cat. No. 22410) then viewed on a Tecnai G2 transmission electron microscope (ThermoFisher, USA).

For the CLEM observation, the ORF3a-GFP, M-mCherry and M-GFP transfected cells were imaged under a confocal light microscope (Ti-RCP, Nikon, Japan) in living cell, and cells were fixed with $1 \%$ glutaraldehyde and $1 \%$ paraformaldehyde in $0.1 \mathrm{M}$ cacodylate solution ( $\mathrm{pH} 7.0$ ). After washing, cells were dehydrated with a graded ethanol series and infiltrated with an embedding medium. Following embedment, $60 \mathrm{~nm}$ sections were cut horizontally to the plane of the block (UC7; Leica Microsystems, Germany) and were mounted on copper slot grids with a specimen support film. Sections were stained with uranyl acetate and lead citrate. The cells were observed at $120 \mathrm{kV}$ in a Tecnai G2 microscope (ThermoFisher, USA). Confocal micrographs were produced as high-quality large images using PhotoZoom Pro 8 software (Benvista Ltd., Houston, TX, USA). Enlarged fluorescence images were fitted to the electron micrographs using the Image J BigWarp program.

\section{Proteome Digestion \& Enrichment of Biotinylated Peptides}

For mass sampling, HEK293T cells were split in three T75 flasks for triplicate samples per each condition. For transiently co-expressed two constructs, vPOI-GFP and TurboID-GBP, cells were grown at $70-80 \%$ confluence and transfected with wanted constructs using PEI. After $16 \mathrm{~h}$ (transfection), $50 \mu \mathrm{M}$ biotin (Alfa aesar, cat. No. A14207) were treated for $30 \mathrm{~min}$ in $37^{\circ} \mathrm{C}$ incubator. After biotin labeling, these cells were washed 3-4 times with cold DPBS and lysed with $1.5 \mathrm{~mL} 2 \%$ SDS in $1 \times$ TBS $(25 \mathrm{mM}$ Tris, $0.15 \mathrm{M} \mathrm{NaCl}, \mathrm{pH}$ 7.2, Thermoscientific, cat. No. 28358) containing $1 \times$ protease inhibitor cocktail. These lysates were underwent ultrasonication (Bioruptor, diagenode) 3-4 times for $15 \mathrm{~min}$ in a cold room. For removing free biotin, 5-6 times the sample volume of cold acetone stored at $-20^{\circ} \mathrm{C}$ (Sigma Aldrich, cat. No. 650501) was mixed with lysates and stored at $-20{ }^{\circ} \mathrm{C}$ for least $2 \mathrm{~h}$. These samples were centrifuged at $13,000 \times \mathrm{g}$ for $10 \mathrm{~min}$ at $4{ }^{\circ} \mathrm{C}$. Supernatant solution was gently discarded. Cold acetone, $6.3 \mathrm{~mL}$, and $700 \mu \mathrm{L}$ of $1 \times$ TBS were mixed with the pellet. These mixtures were then vigorously vortexed and stored at $-20{ }^{\circ} \mathrm{C}$ for least $2 \mathrm{~h}$ or overnight. The samples were then centrifuged at $13,000 \times g$ for an additional $10 \mathrm{~min}$ at $4{ }^{\circ} \mathrm{C}$. Supernatant solution was gently discarded. After pellet was naturally dried for 3-5 min, it was resolubilized with $1 \mathrm{~mL}$ of $8 \mathrm{M}$ urea (Sigma Aldrich, cat. No. U5378) in $50 \mathrm{mM}$ ammonium bicarbonate (ABC, Sigma Aldrich, cat. No. A16141). Protein concentration was calculated using the BCA assay. Samples were vortexed at $650 \mathrm{rpm}$ for $1 \mathrm{~h}$ at $37^{\circ} \mathrm{C}$ using Thermomixer (Eppendorf) for denaturation. Samples were reduced in $10 \mathrm{mM}$ dithiothreitol (Sigma Aldrich, cat. No. 43816) at $650 \mathrm{rpm}$ for $1 \mathrm{~h}$ at $37^{\circ} \mathrm{C}$ using Thermomixer (Eppendorf), while samples alkylation was accomplished in $40 \mathrm{mM}$ iodoacetoamide (Sigma Aldrich, cat. No. I1149) at $650 \mathrm{rpm}$ for $1 \mathrm{~h}$ at $37{ }^{\circ} \mathrm{C}$ using Thermomixer (Eppendorf). These samples were diluted 8 times with $50 \mathrm{mM} \mathrm{ABC} \mathrm{(Sigma} \mathrm{Aldrich,} \mathrm{cat.} \mathrm{No.}$ A16141). $\mathrm{CaCl}_{2}$ (Alfa aesar, cat. No. 12312) was added for the final concentration of $1 \mathrm{mM}$. Samples were digested using trypsin (Thermoscientific, cat. No. 20233) $(50: 1 \mathrm{w} / \mathrm{w})$ at $650 \mathrm{rpm}$ for $6-18 \mathrm{~h}$ at $37^{\circ} \mathrm{C}$ using Thermomixer (Eppendorf). Insoluble materials were removed using centrifugation for $3 \mathrm{~min}$ at $10,000 \times g$. Streptavidin beads (300 $\mu \mathrm{L}$; Pierce, cat. No. 88817) were washed using $2 \mathrm{M}$ urea in $1 \times$ TBS for $3-4$ times, were then added to samples, and then rotated for $1 \mathrm{~h}$ at room temperature. The flow-through fraction was not discarded, and beads were washed 2-3 times using $2 \mathrm{M}$ urea in $50 \mathrm{mM} \mathrm{ABC}$. After removing the supernatants, beads were washed using pure water and transferred to new tubes. After adding $500 \mu \mathrm{L} 80 \%$ acetonitrile (Sigma Aldrich, cat. No. 900667), 0.2\% TFA (Sigma Aldrich, cat. No. T6508) and 0.1\% formic acid (FA, Thermoscientific, cat. No. 28905), heat such biotinylated peptides at $60{ }^{\circ} \mathrm{C}$ and mixed at $650 \mathrm{rpm}$. Supernatant 
without streptavidin beads was transferred to new tubes. This elution step was repeated at least 4 times. These total elution fractions were dried for $5 \mathrm{~h}$ using Speed-vac (Eppendorf). Before samples were injected to mass spectrometry, they were stored at $-20^{\circ} \mathrm{C}$.

\section{Calculation of Similarity Value}

Similarity value of each mass samples was calculated as previously reported. The correlation index, $\mathrm{C}_{\mathrm{ij}}$, was introduced for calculation of similarity value. The Equation below shows how similarity value was calculated.

$$
C_{i j}=\frac{\frac{1}{N} \sum_{k=1}^{N} I_{i}(k) I_{j}(k)}{\sqrt{\frac{1}{N} \sum_{k=1}^{N} I_{i}(k)^{2}} \sqrt{\frac{1}{N} \sum_{k=1}^{N} I_{j}(k)^{2}}}
$$

As the result of $\mathrm{C}_{\mathrm{ij}}$ covers from 0 to 1 , bigger value indicates more similarity, while smaller value indicates less similarity.

\section{LC-MS/MS Analysis of Enriched Peptide Samples}

Analytical capillary columns $(100 \mathrm{~cm} \times 75 \mu \mathrm{m}$ i.d. $)$ and trap columns were packed in-house with $3 \mathrm{~m}$ Jupiter C18 particles (Phenomenex, Torrance). The long analytical column was placed in a column heater (Analytical Sales and Services) regulated to a temperature of $45^{\circ} \mathrm{C}$. NanoAcquity UPLC system (Waters, Milford) was operated at a flow rate of $300 \mathrm{~nL} / \mathrm{min}$ over $2 \mathrm{~h}$ with linear gradient ranging from $95 \%$ solvent $\mathrm{A}\left(\mathrm{H}_{2} \mathrm{O}\right.$ with $0.1 \%$ formic acid) to $40 \%$ of solvent B (acetonitrile with $0.1 \%$ formic acid). The enriched samples were analyzed using Orbitrap Fusion Lumos mass spectrometer (Thermo Scientific) equipped with an in-house customized nanoelectrospray ion source. Precursor ions were acquired $(\mathrm{m} / \mathrm{z} 300-1,500)$ at $120 \mathrm{~K}$ resolving power and the isolation of precursor for MS/MS analysis was conducted with a $1.4 \mathrm{Th}$. Higher-energy collisional dissociation (HCD) with 30\% collision energy was used for sequencing with auto gain control (AGC) target of 1E5. Resolving power for acquired MS2 spectra was set to $30 \mathrm{k}$ at with 200 ms maximum injection time.

\section{Processing MS data and Identification of Proteins}

All MS/MS data were searched using MaxQuant (version 1.5.3.30) with Andromeda search engine at $10 \mathrm{ppm}$ precursor ion mass tolerance against the SwissProt Homo sapiens proteome database (20,199 entries, UniProt (http://www.uniprot.org/)). The label free quantification (LFQ) and Match Between Runs were used with the following search parameters: Semi-trypic digestion, fixed carbaminomethylation on cysteine, dynamic oxidation of methionine, protein $\mathrm{N}$-terminal acetylation with biotin labels of lysine residue. Less than $1 \%$ of false discovery rate (FDR) was obtained for unique labeled peptide and as well as unique labeled protein. LFQ intensity values were log-transformed for further analysis and missing values were filled by imputed values representing a normal distribution around the detection limit. The imputation of protein intensity were conducted using Perseus software program.

\section{ACKNOWLEDGMENTS}

This work was supported by the National Research Foundation of Korea (NRF-2020K1A3A1A47110634, NRF-2019R1A2C3008463), the Organelle Network Research Center (NRF-2017R1A5A1015366) and a grant of the Korea Health Industry Development Institute(KHIDI) funded by the Ministry of Health \& Welfare and Ministry of science and ICT, Republic of Korea (grant number : HU20C0326). H.W.R. was supported by Creative-Pioneering Researchers Program through Seoul National University. J.Y.M. and M.J. are supported by KBRI basic research program through Korea Brain Research Institute funded by Ministry of Science and ICT (Information \& Communication Technology) (20-BR-01-09). EM data were acquired at Brain Research Core Facilities in KBRI. J.-S.K. are supported by IBS-R008-D1 of the Institute for Basic Science from the Ministry of Science and ICT of Korea.

\section{AUTHOR CONTRIBUTIONS}

Y.B.L., J.Y.M., J.S.K., and H.W.R. conceived the project. M.J. and J.Y.M. contributed to EM imaging. J.K. and J.S.K. performed LC-MS/MS experiment and mass data processing. M.G.K. contributed to confocal imaging. C.K. contributed to preparation of mass samples. Y.B.L., J.Y.M., J.S.K., and H.W.R. wrote and edited 
629 the manuscript.

\section{DECLARATION OF INTEREST}

The authors have no conflicting financial interests. A patent application relating to the interactome findings has been filed by Seoul National University.

\section{SUPPLEMENTAL INFORMATION}

\section{Table S1-3.}

Figures S1-S15.

Data S1. Result from mass analysis of ORF3a and M interactome 


\section{FIGURE LEGENDS}

Figure 1. Confocal imaging of GFP-tagged vPOI of SARS-CoV-2 (a) Schematic view of viral protein of interest (vPOI)-linker-GFP constructs (linker sequence: GAPGSAGSAAGSG). Predicted transmembrane (TM) domains by TMHMM program are shown in light gray. (b) Confocal microscopy results of vPOI-GFP constructs in HEK293-AD cells. Scale bars: $10 \mu \mathrm{m}$. (c) Confocal microscopy images of co-expressed N-GFP and G3BP1-V5. G3BP1-V5 was visualized using anti-V5 antibody (AF568-conjugated, red fluorescence channel). Pearson correlation values were calculated between different fluorescent channel images. Scale bars: $8 \mu \mathrm{m}$ (upper) and $10 \mu \mathrm{m}$ (below). BF: bright field.

Figure 2. Interactome mapping of SARS-CoV-2 viral proteins by Spot-TurboID workflow (a) Overview of our Spot-TurboID method combined with vPOI-GFP and TurboID-GBP binding system (b) Confocal microscopy images of vPOI-GFP and TurboID-V5-GBP in HEK293-AD cells. TurboID-V5-GBP was visualized by anti-V5 antibody (AF568-conjugated, RFP fluorescence channel). Biotinylated proteins were visualized by AF647-conjugated streptavidin (Cy5 fluorescence channel). Scale bars: $10 \mu \mathrm{m}$. Additional images are shown in Figure S2. BF: bright field. (c) Streptavidin-horseradish peroxidase (SA-HRP) western blotting results of biotinylated proteins by TurboID-GBP under the co-expression of vPOI-GFP in HEK293T cells. Band signals of biotinylated vPOI-GFP by TurboID-GBP are marked with green asterisks. Anti-V5 blot signals of the same samples are shown below. (d) Anti-GFP western blotting results of the same samples as (c). Bands of the expected molecular weight of each vPOI-GFP constructs are marked with green asterisks. Raw images of blot results are shown in Figure S3.

Figure 3. EM results of ORF3a and Membrane protein of SARS-CoV-2 expressed cells (a) Schematic view of ORF3a-linker-V5-APEX2 and M-linker-V5-APEX2 constructs. Linker sequence: GAPGSAGSAAGSG. TM domains of vPOI are shown in light gray. (b) Proposed membrane topology of ORF3a-APEX2 and M-APEX2 at the ER membrane (c) EM images of DAB-stained ORF3a-APEX2- and ORF3a-GFP-transfected HeLa cells. Scale bars: $1 \mu \mathrm{m}$. Distinct membrane structures were observed with higher magnification. Magnified areas are marked with different colored boxes. Additional EM images are shown in Figure S5a. Parts with red arrows mark DMV structures (c, e, g). Mitochondria and cubic membrane are indicated as " $\mathrm{m}$ " and "CM", respectively (c-g). (d) EM images of M-APEX2 transfected HeLa cells. Scale bars: $1 \mu \mathrm{m}$. Additional EM images are shown in Figure S5b. (e) EM images of ORF3a-APEX2 transfected A549 cells. Scale bas: $500 \mathrm{~nm}-2 \mu \mathrm{m}$. (f) EM images of M-APEX2 transfected A549 cells. Scale bars: $1 \mu \mathrm{m}-$ $2 \mu \mathrm{m}$. (g) CLEM images of ORF3a-GFP and M-mCherry co-transfected A549 cells. Ultrastructures of endomembrane systems in each cell were observed by EM imaging. Scale bars: $500 \mathrm{~nm}-5 \mu \mathrm{m}$.

Figure 4. Mass analysis of host interactome of ORF3a and M protein of SARS-CoV-2 by Spot-TurboID (a) Schematic view of three groups of sample for mass analysis: TurboID-GBP + GFP (left, control), TurboIDGBP + ORF3a-GFP (middle), and TurboID-GBP + M-GFP (right). (b) Enrichment of the Spot-TurboID detected biotinylated proteins by TurboID-GBP in the samples of ORF3a-GFP (upper) or M-GFP (below) over GFP (control), respectively. $x$-axis: $\log _{2}$ value of fold change (FC) of mass signal intensities. cut off value is 2.3 ; y-axis: $-\log _{10}$ value of $p$-value, cut off value is 2.3 . Gene names of the top 30 proteins are shown in the graph. Bubble size indicated the mass signal intensity. See detailed information in Figure S7e and Dataset S1. (c) Subcellular distribution of the selected interactome of ORF3a (117 proteins) and M (191 proteins). See detailed information in Figure S7f and Dataset S1. (d) Gene ontology analysis (http://bioinformatics.sdstate.edu/go/) of enriched functions of ORF3a and M's interactomes. See detailed information in Figure S7g. (e, f) Subcellular map of top 30 selected interactome of ORF3a (e) and M (f). MAM proteins are shown in yellow-colored box. 
Figure 5. Proposed membrane topologies of the integral membrane proteins in ORF3a and M's interactome list. Biotin-labeled sites by TurboID-GBP (cytosolic side) were colored according to their samples (red: observed in ORF3-GFP samples; blue: observed in M-GFP samples; purple: observed both in ORF3a and in M samples). Newly proposed membrane topologies are shown in yellow. Detailed information is given in Figure S8 and Dataset S1.

Figure 6. RNF5 ubiquitinylate ORF3a of SARS-CoV-2. (a) Highlighted RNF5 in ORF3a interactome (left) and in $\mathrm{M}$ interactome (right) volcano plots shown in Figure 4b. (b) Confocal microscopy images of FlagRNF5 in HEK293-AD cells. Flag-RNF5 was visualized by anti-Flag antibody (AF488-conjugated, GFP fluorescence channel). Scale bars: $10 \mu \mathrm{m}$. (c) Confocal microscopy images of vPOI-GFP with Flag-RNF5. Flag-RNF5 was visualized by anti-Flag antibody (AF647-conjugated, Cy5 fluorescence channel). BF: bright field, Scale bars: $10 \mu \mathrm{m}$. (d) Western blot analysis of ORF3a ubiquitination by RNF5 in HEK293T cells. AntiFlag and Anti-V5 were utilized for ORF3a-Flag and V5-UBB, respectively. Red arrow marks the unmodified molecular weight of ORF3a-Flag. Blue arrows mark ubiquitinylated ORF3a-Flag. Same molecular weight bands were detected in both anti-Flag and anti-V5 blot results. Additional blot results are shown in Figure S9d-e and Figure S10. (e) Proposed model of RNF5-mediated ubiquitination of ORF3a of SARS-CoV-2. Zinc finger domain of RNF5 (27-68 aa) is highlighted with yellow box, and 42 aa is an essential site for activity of E3 ubiquitin ligase.

Figure 7. ORF3a remodeled local proteome at the MAM. (a) Local protein overlaps between interactomes of ORF3a (117 proteins), M (191 proteins), and MAM proteome (115 proteins). (b) Pie chart of functionally classified 28 overlapped proteins between ORF3a interactome and MAM proteome. (c) Pie chart of functionally classified 24 overlapped proteins between M interactome and MAM proteome. (d) Scheme of Contact-ID assay to check the MAM proteome changes by ORF3a expression. (e) SA-HRP western blotting results of Contact-ID with or without ORF3a co-expression. Biotinylated ORF3a (lane 4, 5) are marked with red arrow. Additional biotinylated proteins (lane 4,5) are marked with blue arrows. Raw images are shown in Figure S11. (f) Scheme of in situ biotinylation of secreted protein (iSLET) by SEC61B-TurboID. (g) SA-HRP western blotting results of secreted biotinylated proteins from SEC61B-TurboID expressed HEK293 cells with or without co-expression of ORF3a. Raw images are shown in Figure S13a. (h) Anti-strep western blot results of the same samples as (b). Bands of ORF3a-strep (lane 4, 5) are marked with a red arrow. Raw images are shown in Figure S13c. 


\section{Reference}

Alefantis, T., Mostoller, K., Jain, P., Harhaj, E., Grant, C., and Wigdahl, B. (2005). Secretion of the human T cell leukemia virus type I transactivator protein tax. J Biol Chem 280, 17353-17362.

Anderson, P., and Kedersha, N. (2006). RNA granules. J Cell Biol 172, 803-808.

Area-Gomez, E., Del Carmen Lara Castillo, M., Tambini, M.D., Guardia-Laguarta, C., de Groof, A.J.C., Madra, M., Ikenouchi, J., Umeda, M., Bird, T.D., Sturley, S.L., et al. (2012). Upregulated function of mitochondria-associated ER membranes in Alzheimer disease. The EMBO journal 31, 4106-4123.

Ariotti, N., Hall, T.E., Rae, J., Ferguson, C., McMahon, K.A., Martel, N., Webb, R.E., Webb, R.I., Teasdale, R.D., and Parton, R.G. (2015). Modular Detection of GFP-Labeled Proteins for Rapid Screening by Electron Microscopy in Cells and Organisms. Dev Cell 35, 513-525.

Branon, T.C., Bosch, J.A., Sanchez, A.D., Udeshi, N.D., Svinkina, T., Carr, S.A., Feldman, J.L., Perrimon, N., and Ting, A.Y. (2018). Efficient proximity labeling in living cells and organisms with TurboID. Nature Biotechnology 36, 880-887.

Cao, B., Parnell, L.A., Diamond, M.S., and Mysorekar, I.U. (2017). Inhibition of autophagy limits vertical transmission of Zika virus in pregnant mice. Journal of Experimental Medicine 214, 2303-2313.

Cao, Z., Xia, H., Rajsbaum, R., Xia, X., Wang, H., and Shi, P.Y. (2021). Ubiquitination of SARS-CoV-2 ORF7a promotes antagonism of interferon response. Cell Mol Immunol 18, 746-748.

Chan, C.-M., Ma, C.-W., Chan, W.-Y., and Chan, H.Y.E. (2007). The SARS-Coronavirus Membrane protein induces apoptosis through modulating the Akt survival pathway. Archives of Biochemistry and Biophysics 459, 197-207.

Chan, C.M., Tsoi, H., Chan, W.M., Zhai, S., Wong, C.O., Yao, X., Chan, W.Y., Tsui, S.K., and Chan, H.Y. (2009). The ion channel activity of the SARS-coronavirus 3a protein is linked to its pro-apoptotic function. Int J Biochem Cell Biol 41, 2232-2239.

Cortese, M., Lee, J.Y., Cerikan, B., Neufeldt, C.J., Oorschot, V.M.J., Kohrer, S., Hennies, J., Schieber, N.L., Ronchi, P., Mizzon, G., et al. (2020). Integrative Imaging Reveals SARS-CoV-2-Induced Reshaping of Subcellular Morphologies. Cell Host Microbe 28, 853-866 e855.

Davies, J.P., Almasy, K.M., McDonald, E.F., and Plate, L. (2020). Comparative multiplexed interactomics of SARS-CoV-2 and homologous coronavirus non-structural proteins identifies unique and shared host-cell dependencies. bioRxiv, 2020.2007.2013.201517.

Delprat, B., Maurice, T., and Delettre, C. (2018). Wolfram syndrome: MAMs' connection? Cell Death Dis 9 , 364.

Deng, Y., and Angelova, A. (2021). Coronavirus-Induced Host Cubic Membranes and Lipid-Related Antiviral Therapies: A Focus on Bioactive Plasmalogens. Front Cell Dev Biol 9, 630242.

Dörner, A., Xiong, D., Couch, K., Yajima, T., and Knowlton, K.U. (2004). Alternatively spliced soluble coxsackie-adenovirus receptors inhibit coxsackievirus infection. J Biol Chem 279, 18497-18503.

Fang, X., Gao, J., Zheng, H., Li, B., Kong, L., Zhang, Y., Wang, W., Zeng, Y., and Ye, L. (2007). The membrane protein of SARS-CoV suppresses NF-kappaB activation. J Med Virol 79, 1431-1439.

Fernández de Castro, I., Zamora, P.F., Ooms, L., Fernández, J.J., Lai, C.M., Mainou, B.A., Dermody, T.S., and Risco, C. (2014). Reovirus forms neo-organelles for progeny particle assembly within reorganized cell membranes. mBio 5 .

Fung, T.S., Huang, M., and Liu, D.X. (2014). Coronavirus-induced ER stress response and its involvement in regulation of coronavirus-host interactions. Virus Res 194, 110-123.

Gordon, D.E., Jang, G.M., Bouhaddou, M., Xu, J., Obernier, K., White, K.M., O'Meara, M.J., Rezelj, V.V., Guo, J.Z., Swaney, D.L., et al. (2020). A SARS-CoV-2 protein interaction map reveals targets for drug repurposing. Nature 583, 459-468.

Hamamoto, I., Nishimura, Y., Okamoto, T., Aizaki, H., Liu, M., Mori, Y., Abe, T., Suzuki, T., Lai, M.M., Miyamura, T., et al. (2005). Human VAP-B is involved in hepatitis $\mathrm{C}$ virus replication through interaction with NS5A and NS5B. J Virol 79, 13473-13482.

Hamasaki, M., Furuta, N., Matsuda, A., Nezu, A., Yamamoto, A., Fujita, N., Oomori, H., Noda, T., Haraguchi, T., Hiraoka, Y., et al. (2013). Autophagosomes form at ER-mitochondria contact sites. Nature 495, 389-393. Hamel, R., Dejarnac, O., Wichit, S., Ekchariyawat, P., Neyret, A., Luplertlop, N., Perera-Lecoin, M., Surasombatpattana, P., Talignani, L., Thomas, F., et al. (2015). Biology of Zika Virus Infection in Human Skin 
Cells. J Virol 89, 8880-8896.

Hariri, M., Millane, G., Guimond, M.P., Guay, G., Dennis, J.W., and Nabi, I.R. (2000). Biogenesis of multilamellar bodies via autophagy. Mol Biol Cell 11, 255-268.

Inoue, T., and Tsai, B. (2013). How viruses use the endoplasmic reticulum for entry, replication, and assembly. Cold Spring Harb Perspect Biol 5, a013250.

Issa, E., Merhi, G., Panossian, B., Salloum, T., and Tokajian, S. (2020). SARS-CoV-2 and ORF3a: Nonsynonymous Mutations, Functional Domains, and Viral Pathogenesis. mSystems 5.

Kern, D.M., Sorum, B., Hoel, C.M., Sridharan, S., Remis, J.P., Toso, D.B., and Brohawn, S.G. (2020). CryoEM structure of the SARS-CoV-2 3a ion channel in lipid nanodiscs. bioRxiv : the preprint server for biology, 2020.2006.2017.156554.

Kerns, J.A., Emerman, M., and Malik, H.S. (2008). Positive selection and increased antiviral activity associated with the PARP-containing isoform of human zinc-finger antiviral protein. PLoS Genet 4, e21.

Kim, K.-e., Park, I., Kim, J., Kang, M.-G., Choi, W.G., Shin, H., Kim, J.-S., Rhee, H.-W., and Suh, J.M. (2020). Dynamic tracking and identification of tissue-specific secretory proteins in the circulation of live mice. bioRxiv, 2020.2009.2021.299198.

Klein, S., Cortese, M., Winter, S.L., Wachsmuth-Melm, M., Neufeldt, C.J., Cerikan, B., Stanifer, M.L., Boulant, S., Bartenschlager, R., and Chlanda, P. (2020). SARS-CoV-2 structure and replication characterized by in situ cryo-electron tomography. Nat Commun 11, 5885.

Konno, Y., Kimura, I., Uriu, K., Fukushi, M., Irie, T., Koyanagi, Y., Sauter, D., Gifford, R.J., Nakagawa, S., and Sato, K. (2020). SARS-CoV-2 ORF3b Is a Potent Interferon Antagonist Whose Activity Is Increased by a Naturally Occurring Elongation Variant. Cell Reports 32, 108185.

Kuang, E., Okumura, C.Y., Sheffy-Levin, S., Varsano, T., Shu, V.C., Qi, J., Niesman, I.R., Yang, H.J., LopezOtin, C., Yang, W.Y., et al. (2012). Regulation of ATG4B stability by RNF5 limits basal levels of autophagy and influences susceptibility to bacterial infection. PLoS Genet 8, e1003007.

Kwak, C., Shin, S., Park, J.S., Jung, M., Nhung, T.T.M., Kang, M.G., Lee, C., Kwon, T.H., Park, S.K., Mun, J.Y., et al. (2020). Contact-ID, a tool for profiling organelle contact sites, reveals regulatory proteins of mitochondrial-associated membrane formation. Proc Natl Acad Sci U S A 117, 12109-12120.

Laurent, E.M.N., Sofianatos, Y., Komarova, A., Gimeno, J.-P., Tehrani, P.S., Kim, D.-K., Abdouni, H., Duhamel, M., Cassonnet, P., Knapp, J.J., et al. (2020). Global BioID-based SARS-CoV-2 proteins proximal interactome unveils novel ties between viral polypeptides and host factors involved in multiple COVID19associated mechanisms. bioRxiv, 2020.2008.2028.272955.

Lee, H., Komano, J., Saitoh, Y., Yamaoka, S., Kozaki, T., Misawa, T., Takahama, M., Satoh, T., Takeuchi, O., Yamamoto, N., et al. (2013). Zinc-finger antiviral protein mediates retinoic acid inducible gene I-like receptorindependent antiviral response to murine leukemia virus. Proc Natl Acad Sci U S A 110, 12379-12384.

Lee, S.Y., Lee, H., Lee, H.K., Lee, S.W., Ha, S.C., Kwon, T., Seo, J.K., Lee, C., and Rhee, H.W. (2016). Proximity-Directed Labeling Reveals a New Rapamycin-Induced Heterodimer of FKBP25 and FRB in Live Cells. Acs Central Sci 2, 506-516.

Lee, S.Y., Seo, J.K., and Rhee, H.W. (2019). Direct Identification of Biotinylated Proteins from Proximity Labeling (Spot-BioID). Methods Mol Biol 2008, 97-105.

Lee, Y.R., Kuo, S.H., Lin, C.Y., Fu, P.J., Lin, Y.S., Yeh, T.M., and Liu, H.S. (2018). Dengue virus-induced ER stress is required for autophagy activation, viral replication, and pathogenesis both in vitro and in vivo. Sci Rep 8, 489.

Li, Y., Tinoco, R., Elmén, L., Segota, I., Xian, Y., Fujita, Y., Sahu, A., Zarecki, R., Marie, K., Feng, Y., et al. (2019). Gut microbiota dependent anti-tumor immunity restricts melanoma growth in Rnf5(-/-) mice. Nat Commun 10, 1492.

Lietzén, N., Hirvonen, K., Honkimaa, A., Buchacher, T., Laiho, J.E., Oikarinen, S., Mazur, M.A., FlodströmTullberg, M., Dufour, E., Sioofy-Khojine, A.B., et al. (2019). Coxsackievirus B Persistence Modifies the Proteome and the Secretome of Pancreatic Ductal Cells. iScience 19, 340-357.

Lin, J.H., Walter, P., and Yen, T.S. (2008). Endoplasmic reticulum stress in disease pathogenesis. Annu Rev Pathol 3, 399-425.

Martell, J.D., Deerinck, T.J., Sancak, Y., Poulos, T.L., Mootha, V.K., Sosinsky, G.E., Ellisman, M.H., and Ting, A.Y. (2012). Engineered ascorbate peroxidase as a genetically encoded reporter for electron microscopy. Nature Biotechnology 30, 1143-1148. 
Martino, T.A., Petric, M., Weingartl, H., Bergelson, J.M., Opavsky, M.A., Richardson, C.D., Modlin, J.F., Finberg, R.W., Kain, K.C., Willis, N., et al. (2000). The coxsackie-adenovirus receptor (CAR) is used by reference strains and clinical isolates representing all six serotypes of coxsackievirus group B and by swine vesicular disease virus. Virology 271, 99-108.

Miao, G., Zhao, H., Li, Y., Ji, M., Chen, Y., Shi, Y., Bi, Y., Wang, P., and Zhang, H. (2021). ORF3a of the COVID-19 virus SARS-CoV-2 blocks HOPS complex-mediated assembly of the SNARE complex required for autolysosome formation. Dev Cell 56, 427-442 e425.

Monel, B., Compton, A.A., Bruel, T., Amraoui, S., Burlaud-Gaillard, J., Roy, N., Guivel-Benhassine, F., Porrot, F., Génin, P., Meertens, L., et al. (2017). Zika virus induces massive cytoplasmic vacuolization and paraptosislike death in infected cells. EMBO J 36, 1653-1668.

Nii, S., Morgan, C., and Rose, H.M. (1968). Electron microscopy of herpes simplex virus. II. Sequence of development. J Virol 2, 517-536.

Niphakis, M.J., Lum, K.M., Cognetta, A.B., 3rd, Correia, B.E., Ichu, T.-A., Olucha, J., Brown, S.J., Kundu, S., Piscitelli, F., Rosen, H., et al. (2015). A Global Map of Lipid-Binding Proteins and Their Ligandability in Cells. Cell 161, 1668-1680.

Nover, L., Scharf, K.D., and Neumann, D. (1983). Formation of cytoplasmic heat shock granules in tomato cell cultures and leaves. Mol Cell Biol 3, 1648-1655.

Oshiumi, H., Mifsud, E.J., and Daito, T. (2015). Links between recognition and degradation of cytoplasmic viral RNA in innate immune response. Reviews in medical virology 26, 90-101.

Petrosyan, A., Cheng, P.W., Clemens, D.L., and Casey, C.A. (2015). Downregulation of the small GTPase SAR1A: a key event underlying alcohol-induced Golgi fragmentation in hepatocytes. Sci Rep 5, 17127.

Phillips, M.J., and Voeltz, G.K. (2016). Structure and function of ER membrane contact sites with other organelles. Nat Rev Mol Cell Biol 17, 69-82.

Qin, L., Jeng, H., Rakue, Y., and Mizota, T. (2005). A deficient public health system as a contributing cause of Severe Acute Respiratory Syndrome (SARS) epidemic in mainland China. Southeast Asian J Trop Med Public Health 36, 213-216.

Rahman, M.A., Islam, K., Rahman, S., and Alamin, M. (2020). Neurobiochemical Cross-talk Between COVID-19 and Alzheimer's Disease. Molecular Neurobiology.

Ren, Y., Shu, T., Wu, D., Mu, J., Wang, C., Huang, M., Han, Y., Zhang, X.Y., Zhou, W., Qiu, Y., et al. (2020). The ORF3a protein of SARS-CoV-2 induces apoptosis in cells. Cell Mol Immunol 17, 881-883.

Rhee, H.W., Zou, P., Udeshi, N.D., Martell, J.D., Mootha, V.K., Carr, S.A., and Ting, A.Y. (2013). Proteomic mapping of mitochondria in living cells via spatially restricted enzymatic tagging. Science 339, 1328-1331.

Roux, K.J., Kim, D.I., Raida, M., and Burke, B. (2012). A promiscuous biotin ligase fusion protein identifies proximal and interacting proteins in mammalian cells. J Cell Biol 196, 801-810.

Samavarchi-Tehrani, P., Abdouni, H., Knight, J.D.R., Astori, A., Samson, R., Lin, Z.-Y., Kim, D.-K., Knapp, J.J., St-Germain, J., Go, C.D., et al. (2020). A SARS-CoV-2 - host proximity interactome. bioRxiv, 2020.2009.2003.282103.

Sanz-Sánchez, L., and Risco, C. (2013). Multilamellar structures and filament bundles are found on the cell surface during bunyavirus egress. PLoS One 8, e65526.

Schon, E.A., and Przedborski, S. (2011). Mitochondria: the next (neurode)generation. Neuron 70, 1033-1053. Schuck, S., Gallagher, C.M., and Walter, P. (2014). ER-phagy mediates selective degradation of endoplasmic reticulum independently of the core autophagy machinery. J Cell Sci 127, 4078-4088.

Shuo Yang, M.T., Aron N Johnson (2020). SARS-CoV-2 protein ORF3a is pathogenic in Drosophila and causes phenotypes associated with COVID-19 post-viral syndrome. bioRxiv.

Siu, K.L., Yuen, K.S., Castaño-Rodriguez, C., Ye, Z.W., Yeung, M.L., Fung, S.Y., Yuan, S., Chan, C.P., Yuen, K.Y., Enjuanes, L., et al. (2019). Severe acute respiratory syndrome coronavirus ORF3a protein activates the NLRP3 inflammasome by promoting TRAF3-dependent ubiquitination of ASC. Faseb j 33, 8865-8877.

Snapp, E.L., Hegde, R.S., Francolini, M., Lombardo, F., Colombo, S., Pedrazzini, E., Borgese, N., and Lippincott-Schwartz, J. (2003). Formation of stacked ER cisternae by low affinity protein interactions. J Cell Biol 163, 257-269.

Snijder, E.J., Limpens, R., de Wilde, A.H., de Jong, A.W.M., Zevenhoven-Dobbe, J.C., Maier, H.J., Faas, F., Koster, A.J., and Barcena, M. (2020). A unifying structural and functional model of the coronavirus replication organelle: Tracking down RNA synthesis. PLoS Biol 18, e3000715. 
St-Germain, J.R., Astori, A., Samavarchi-Tehrani, P., Abdouni, H., Macwan, V., Kim, D.-K., Knapp, J.J., Roth, F.P., Gingras, A.-C., and Raught, B. (2020). A SARS-CoV-2 BioID-based virus-host membrane protein interactome and virus peptide compendium: new proteomics resources for COVID-19 research. bioRxiv, 2020.2008.2028.269175.

Stertz, S., Reichelt, M., Spiegel, M., Kuri, T., Martínez-Sobrido, L., García-Sastre, A., Weber, F., and Kochs, G. (2007). The intracellular sites of early replication and budding of SARS-coronavirus. Virology 361, 304315.

Stukalov, A., Girault, V., Grass, V., Karayel, O., Bergant, V., Urban, C., Haas, D.A., Huang, Y., Oubraham, L., Wang, A., et al. (2021). Multilevel proteomics reveals host perturbations by SARS-CoV-2 and SARS-CoV. Nature.

Tenorio, R., Fernández de Castro, I., Knowlton, J.J., Zamora, P.F., Lee, C.H., Mainou, B.A., Dermody, T.S., and Risco, C. (2018). Reovirus $\sigma \mathrm{NS}$ and $\mu$ NS Proteins Remodel the Endoplasmic Reticulum to Build Replication Neo-Organelles. mBio 9.

Tubbs, E., Chanon, S., Robert, M., Bendridi, N., Bidaux, G., Chauvin, M.-A., Ji-Cao, J., Durand, C., GauvritRamette, D., Vidal, H., et al. (2018). Disruption of Mitochondria-Associated Endoplasmic Reticulum Membrane (MAM) Integrity Contributes to Muscle Insulin Resistance in Mice and Humans. Diabetes 67, 636. Uchil, P.D., and Satchidanandam, V. (2003). Architecture of the flaviviral replication complex. Protease, nuclease, and detergents reveal encasement within double-layered membrane compartments. J Biol Chem 278, 24388-24398.

V'Kovski, P., Gerber, M., Kelly, J., Pfaender, S., Ebert, N., Braga Lagache, S., Simillion, C., Portmann, J., Stalder, H., Gaschen, V., et al. (2019). Determination of host proteins composing the microenvironment of coronavirus replicase complexes by proximity-labeling. Elife 8 .

Wang, K., Lu, W., Chen, J., Xie, S., Shi, H., Hsu, H., Yu, W., Xu, K., Bian, C., Fischer, W.B., et al. (2012a). PEDV ORF3 encodes an ion channel protein and regulates virus production. FEBS Lett 586, 384-391.

Wang, X., Tu, F., Zhu, Y., and Gao, G. (2012b). Zinc-Finger Antiviral Protein Inhibits XMRV Infection. PLOS ONE 7, e39159.

Wolff, G., Limpens, R., Zevenhoven-Dobbe, J.C., Laugks, U., Zheng, S., de Jong, A.W.M., Koning, R.I., Agard, D.A., Grunewald, K., Koster, A.J., et al. (2020). A molecular pore spans the double membrane of the coronavirus replication organelle. Science 369, 1395-1398.

Xie, L., Song, X.-j., Liao, Z.-f., Wu, B., Yang, J., Zhang, H., and Hong, J. (2019). Endoplasmic reticulum remodeling induced by Wheat yellow mosaic virus infection studied by transmission electron microscopy. Micron 120, 80-90.

Zhang, Y., Sun, H., Pei, R., Mao, B., Zhao, Z., Li, H., Lin, Y., and Lu, K. (2021). The SARS-CoV-2 protein ORF3a inhibits fusion of autophagosomes with lysosomes. Cell Discov 7, 31.

Zhen Yuan, B.H., Yulei Wang, Xuan Tan, Hurong Xiao, Mengzhen Yue, Kun Cai, Ke Tang, Binbin Ding (2021). The E3 ubiquitin ligase RNF5 facilitates SARS-CoV-2 membrane protein-mediated virion release. bioRxiv. Zhong, B., Zhang, L., Lei, C., Li, Y., Mao, A.P., Yang, Y., Wang, Y.Y., Zhang, X.L., and Shu, H.B. (2009). The ubiquitin ligase RNF5 regulates antiviral responses by mediating degradation of the adaptor protein MITA. Immunity 30, 397-407.

Zhong, B., Zhang, Y., Tan, B., Liu, T.T., Wang, Y.Y., and Shu, H.B. (2010). The E3 ubiquitin ligase RNF5 targets virus-induced signaling adaptor for ubiquitination and degradation. J Immunol 184, 6249-6255.

Zhou, Z., Ren, L., Zhang, L., Zhong, J., Xiao, Y., Jia, Z., Guo, L., Yang, J., Wang, C., Jiang, S., et al. (2020). Heightened Innate Immune Responses in the Respiratory Tract of COVID-19 Patients. Cell Host Microbe 27, 883-890.e882.

Zhu, Y., Chen, G., Lv, F., Wang, X., Ji, X., Xu, Y., Sun, J., Wu, L., Zheng, Y.-T., and Gao, G. (2011). Zincfinger antiviral protein inhibits HIV-1 infection by selectively targeting multiply spliced viral mRNAs for degradation. Proc Natl Acad Sci U S A 108, 15834-15839.

Zou, D., Xu, J., Duan, X., Xu, X., Li, P., Cheng, L., Zheng, L., Li, X., Zhang, Y., Wang, X., et al. (2019). Porcine epidemic diarrhea virus ORF3 protein causes endoplasmic reticulum stress to facilitate autophagy. Vet Microbiol 235, 209-219. 


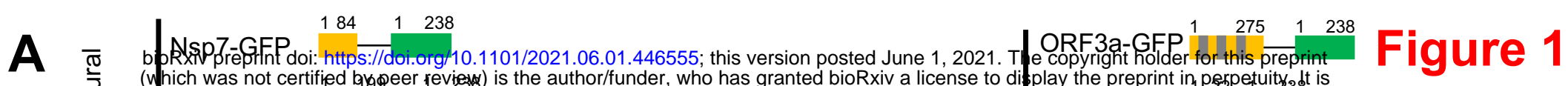

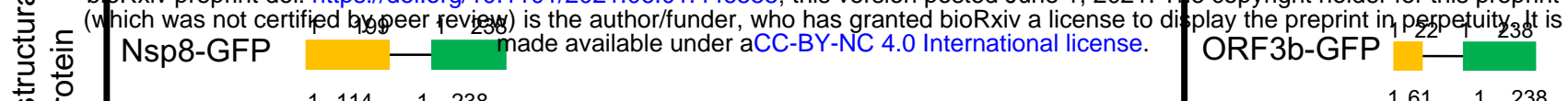

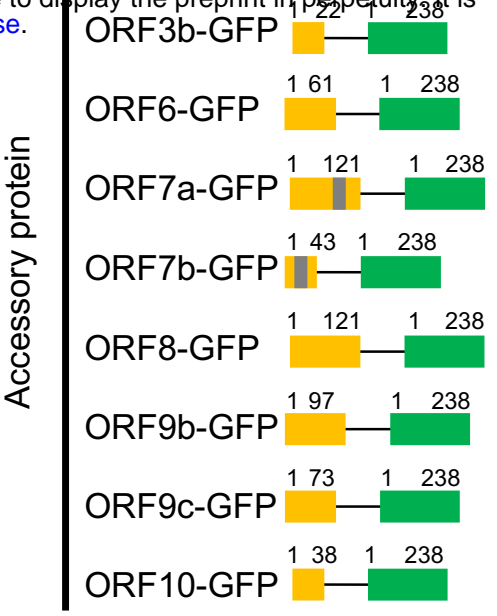

B
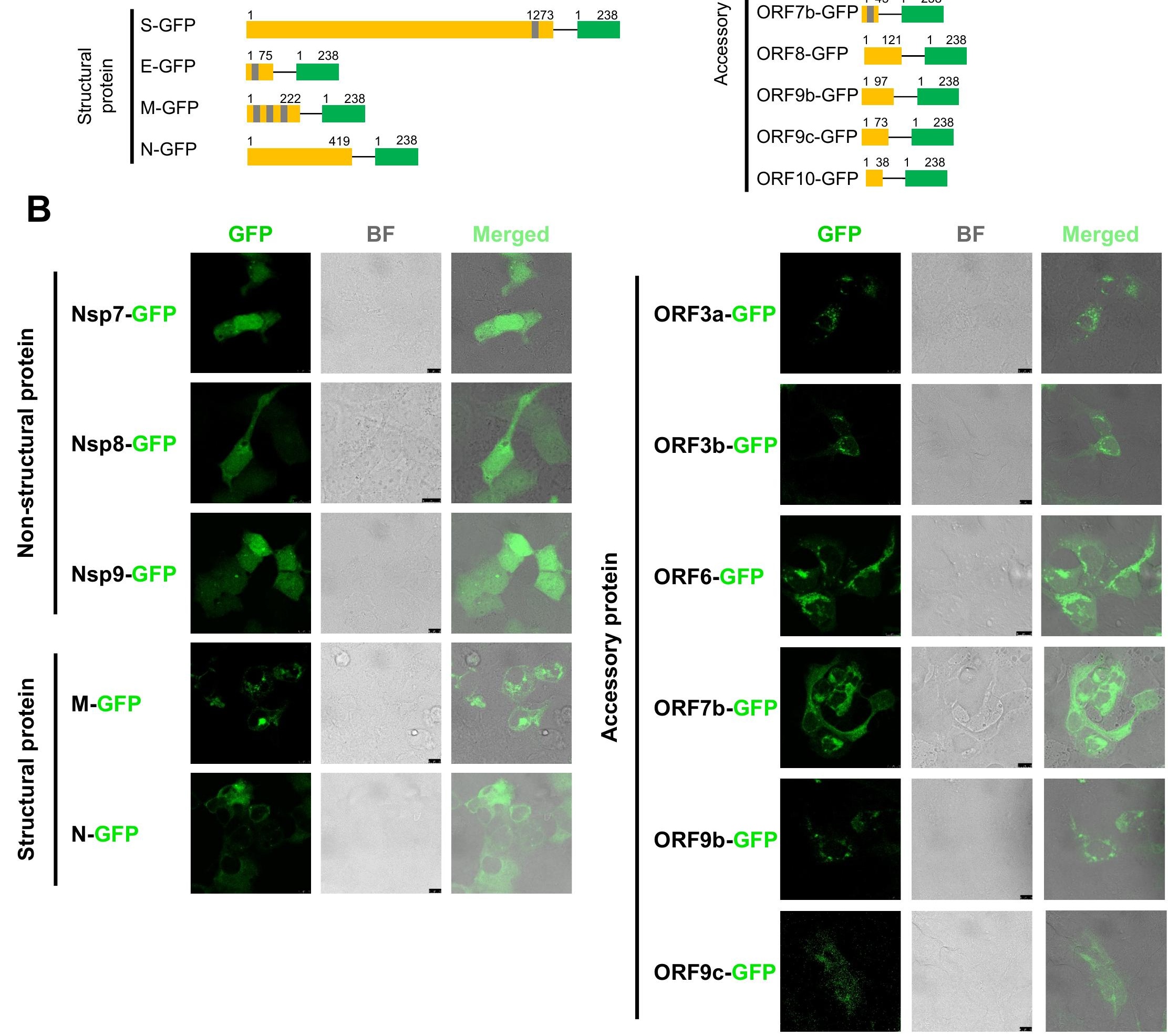

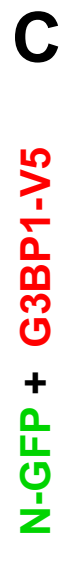

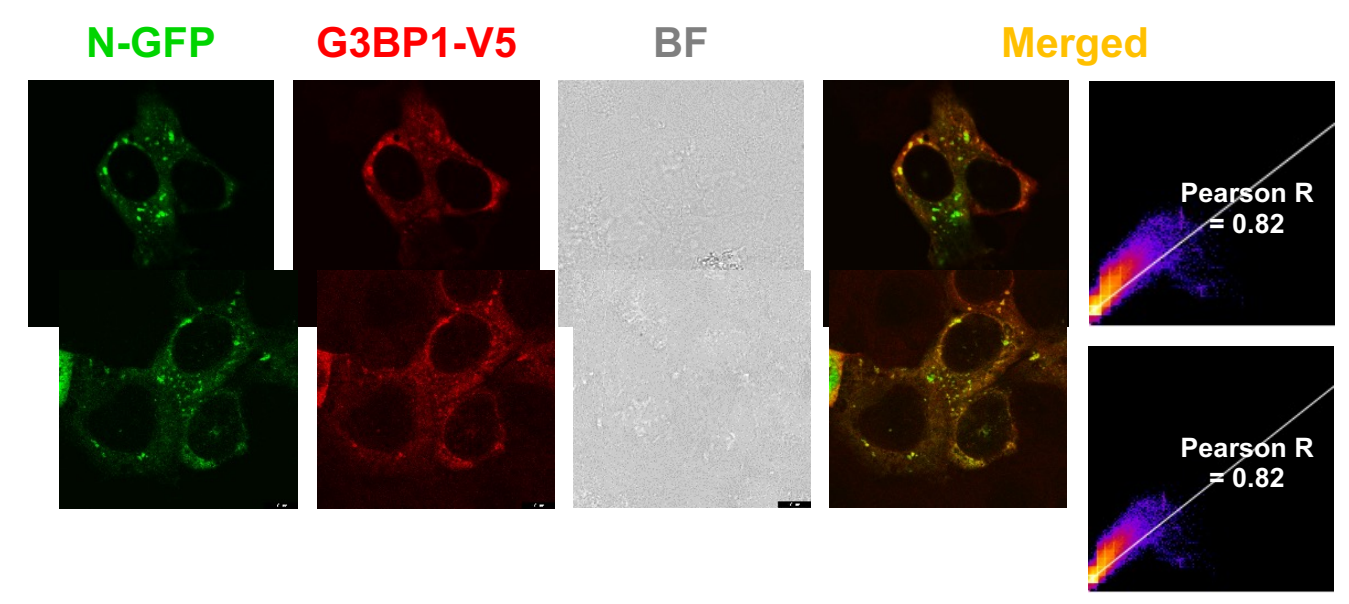



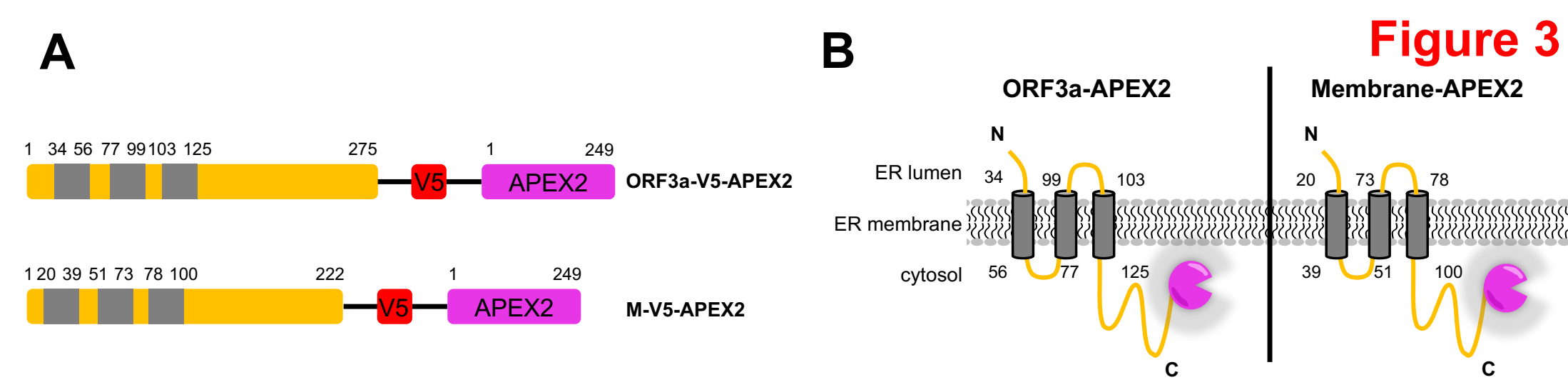
Membrane-APEX2 N
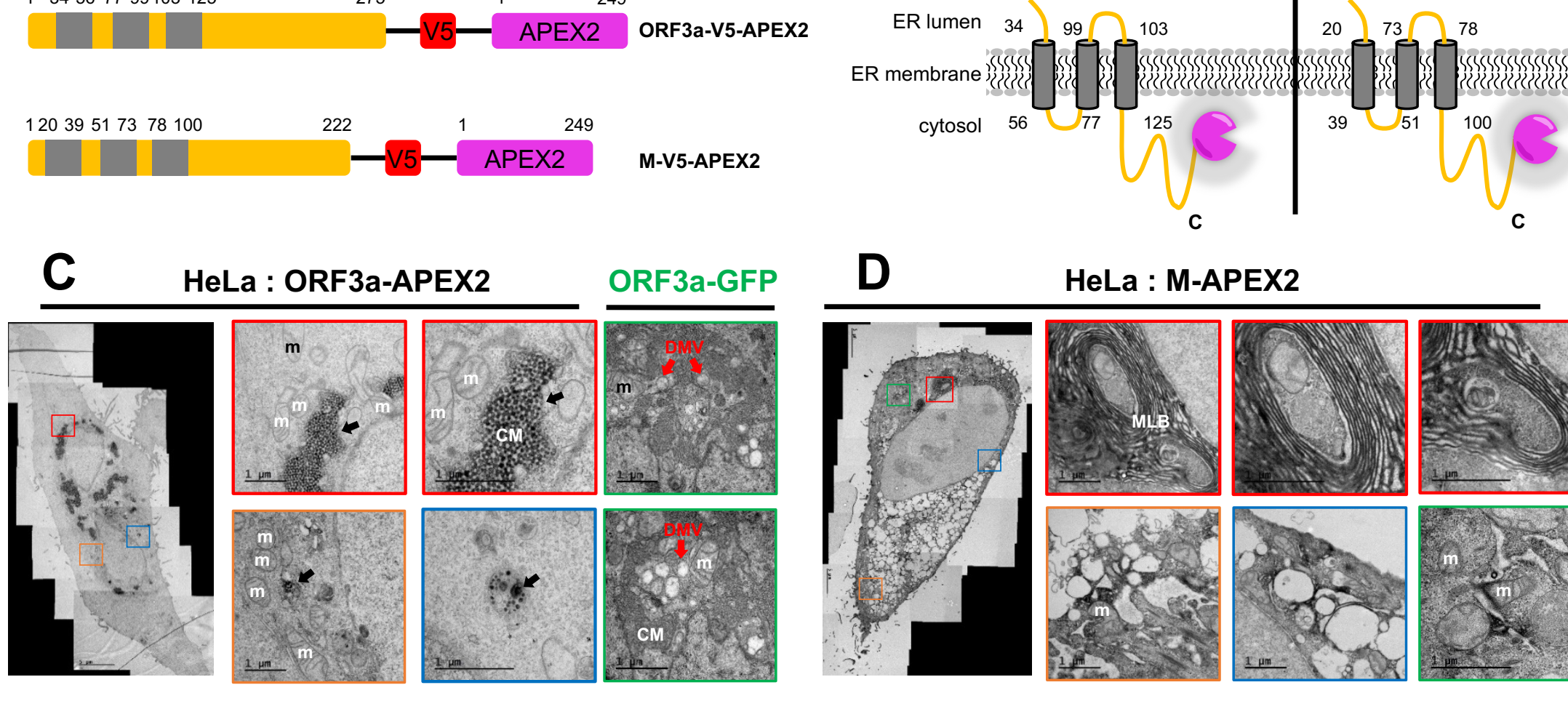

D HeLa : M-APEX2
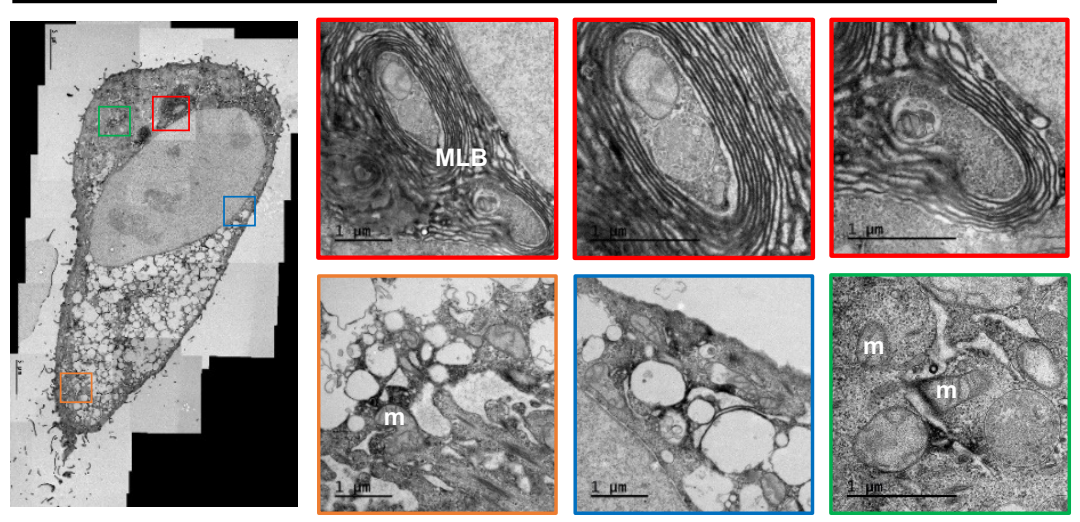

E

A549 : ORF3a-APEX2

$F$

A549 : M-APEX2
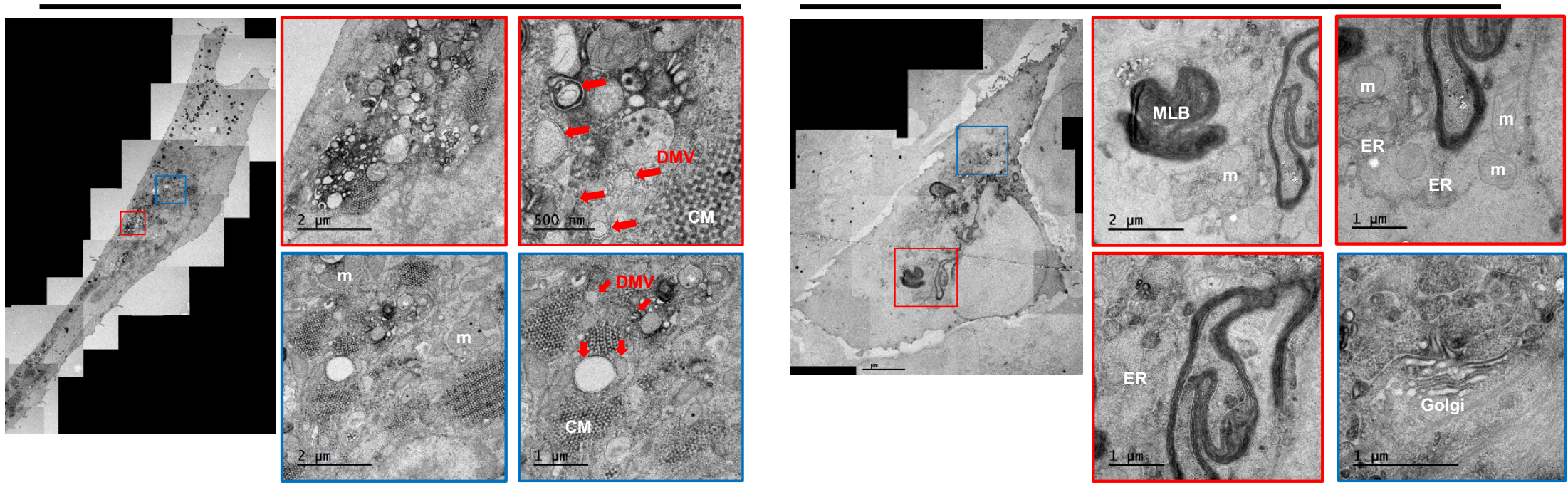

G

A549 : ORF3a-GFP + M-mCherry

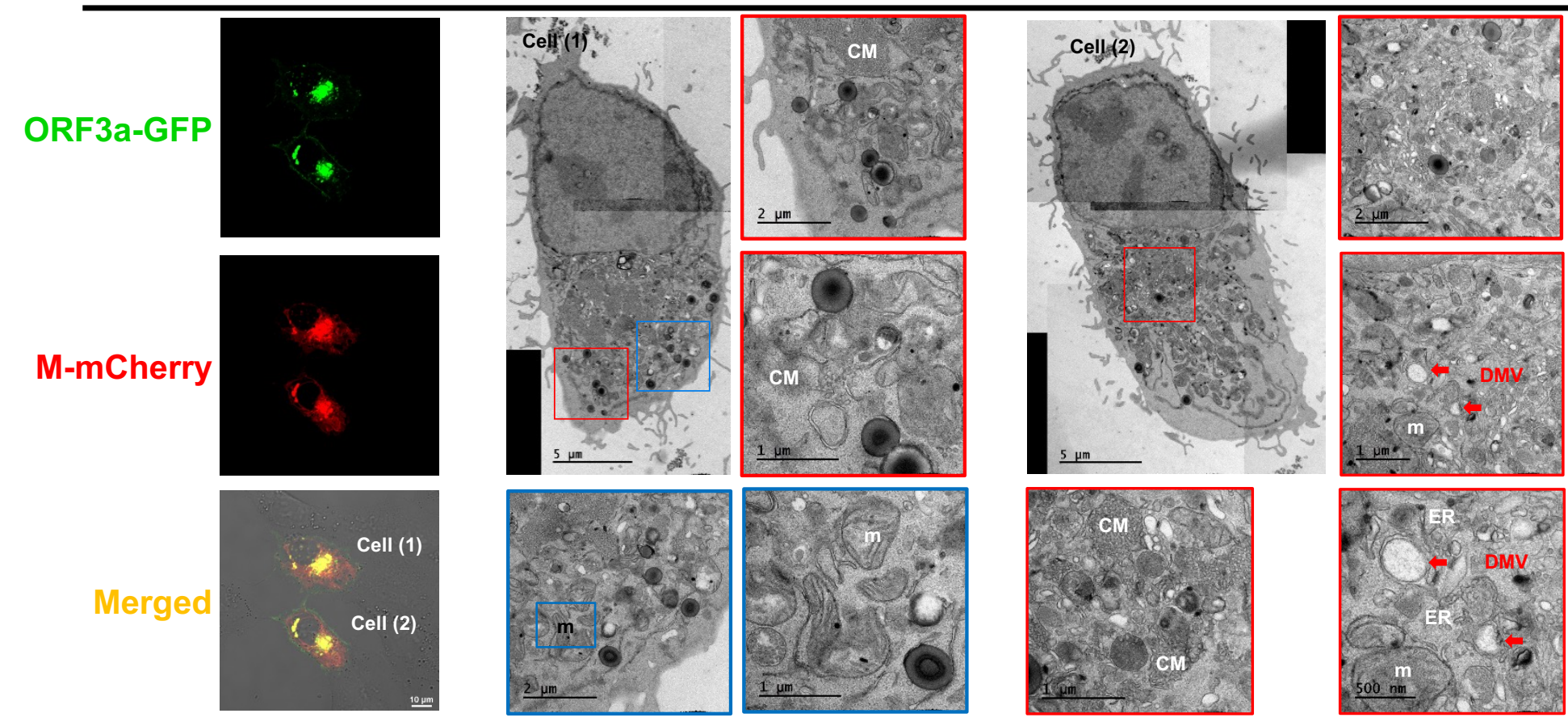


A

\section{Ctrl : GFP + TurbolD-GBP}

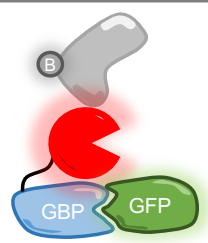

ORF3a-GFP + TurbolD-GBP

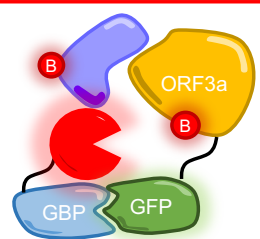

B

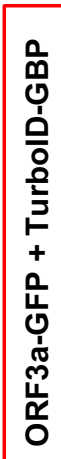

117 proteins selected as ORF3a interactome

$\log _{2} \mathrm{FC} \geq 2.3$

- Log 10 p-value $\geq 2.3$

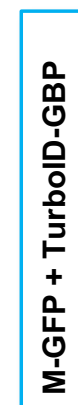

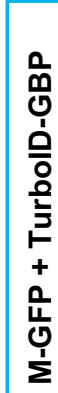

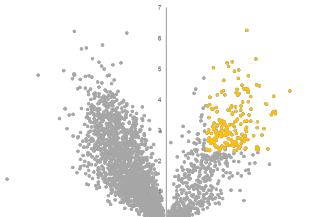

191 proteins selected as $\mathrm{M}$ interactome

$\log _{2} F C \geq 2.3$

Log 10 p-value $\geq 2.3$
Among 117 proteins

Top 30 interactome selected as intensity of mass signal

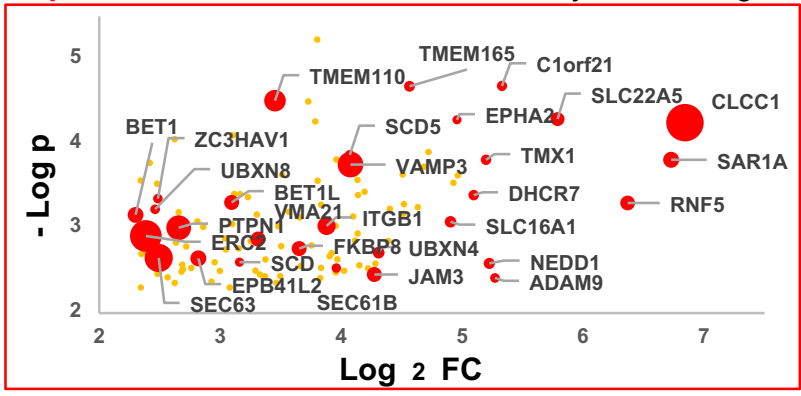

Among 191 proteins

Top 30 interactome selected as intensity of mass signal

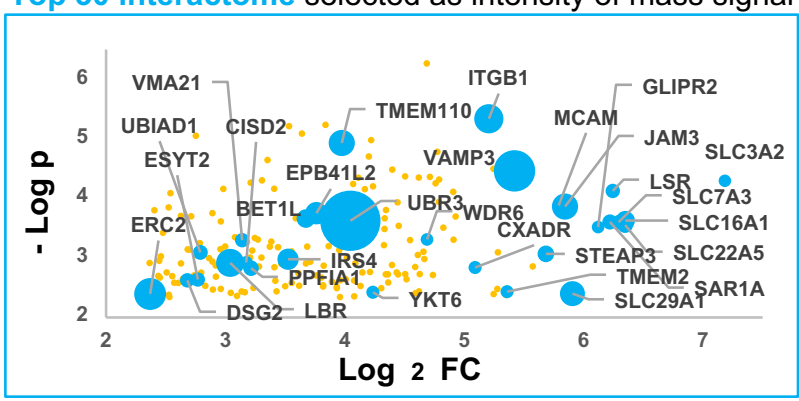

M-GFP + TurbolD-GBP

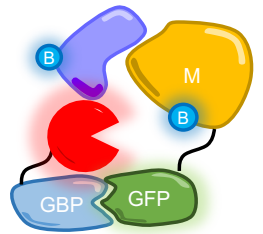

Figure 4

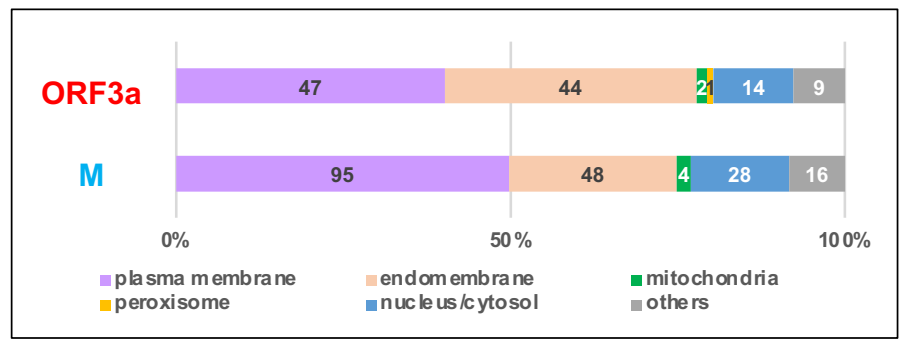

D

\begin{tabular}{|c|c|c|c|}
\hline ORF3a GO analysis & $\begin{array}{l}\text { Enrichment } \\
\text { FDR }\end{array}$ & M GO analysis & $\begin{array}{l}\text { Enrichment } \\
\text { FDR }\end{array}$ \\
\hline Regulation of localization & $2.89 \mathrm{E}-05$ & $\begin{array}{r}\text { Protein } \\
\text { localization }\end{array}$ & $8.11 \mathrm{E}-12$ \\
\hline $\begin{array}{r}\text { Ubiquitin-dependent } \\
\text { ERAD pathway }\end{array}$ & 0.000204 & $\begin{array}{r}\text { Nitrogen compound } \\
\text { transport }\end{array}$ & $1.35 \mathrm{E}-11$ \\
\hline $\begin{array}{l}\text { Regulation of sterol } \\
\text { biosynthetic process }\end{array}$ & 0.000431 & $\begin{array}{r}\text { Organic substance } \\
\text { transport }\end{array}$ & $1.45 \mathrm{E}-11$ \\
\hline $\begin{array}{l}\text { Regulation of cholesterol } \\
\text { biosynthetic process }\end{array}$ & 0.000431 & $\begin{array}{l}\text { Establishment of } \\
\text { protein localization }\end{array}$ & $3.45 \mathrm{E}-11$ \\
\hline $\begin{array}{r}\text { Protein exit from } \\
\text { endoplasmic reticulum }\end{array}$ & 0.000431 & $\begin{array}{r}\text { Macromolecule } \\
\text { localization }\end{array}$ & $1.31 \mathrm{E}-10$ \\
\hline
\end{tabular}

E

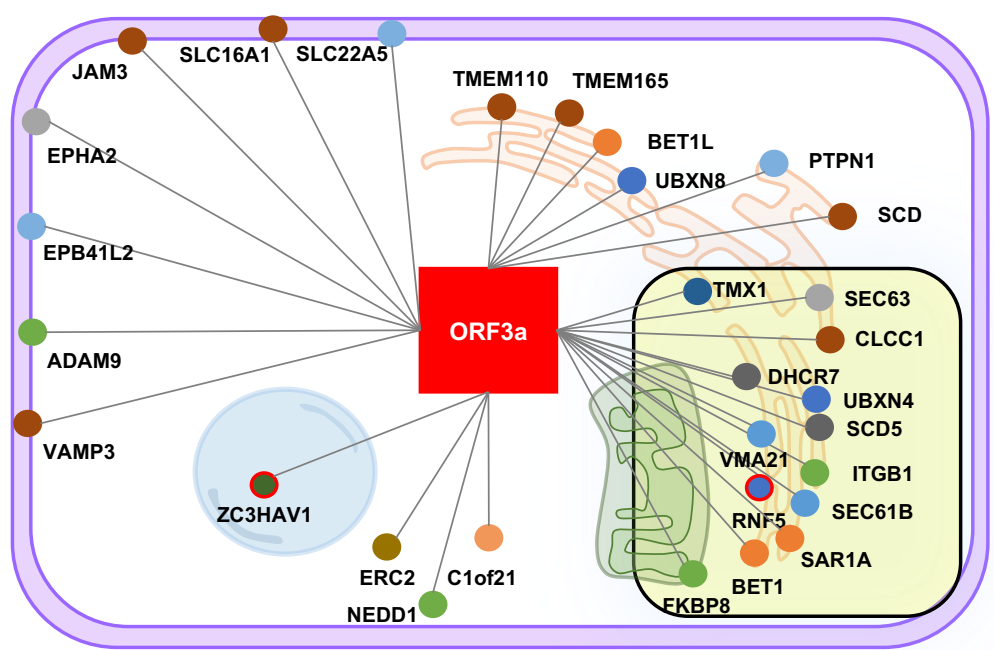

$\mathbf{F}$

Protein transport and chaperone

Vesicle transport

Membrane integrity

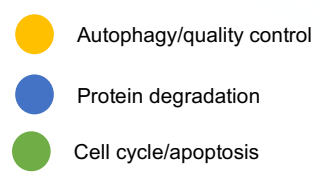

Redox reaction

Ion transport

Lipid synthesis and steroid binding/process

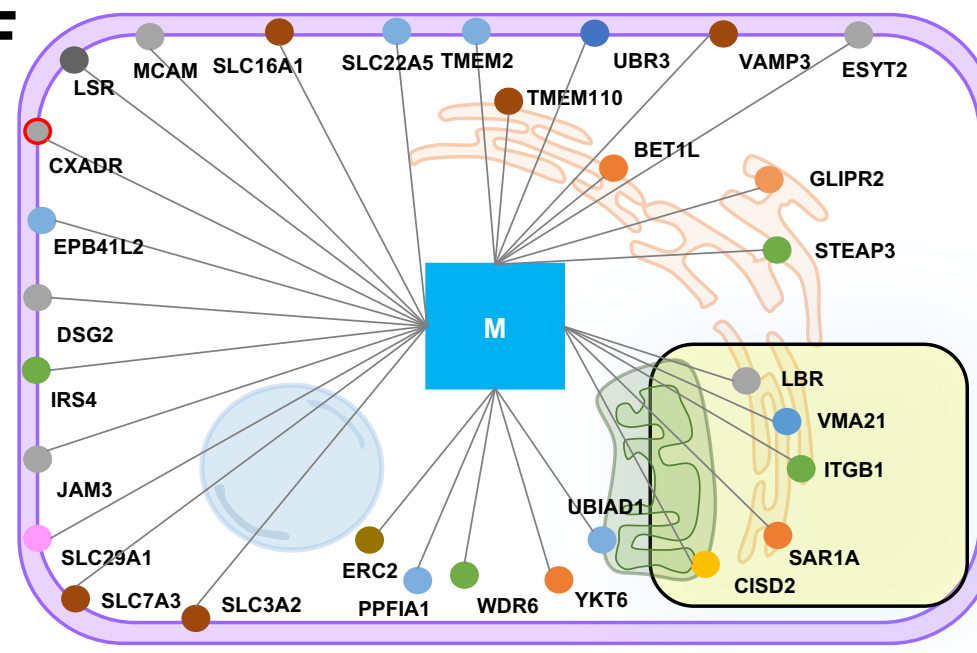

SLC7A3

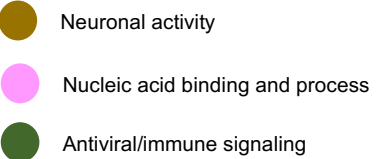

Antiviral/immune signaling
Others

Unknown

Proteins characterized as interacting with viral proteins 


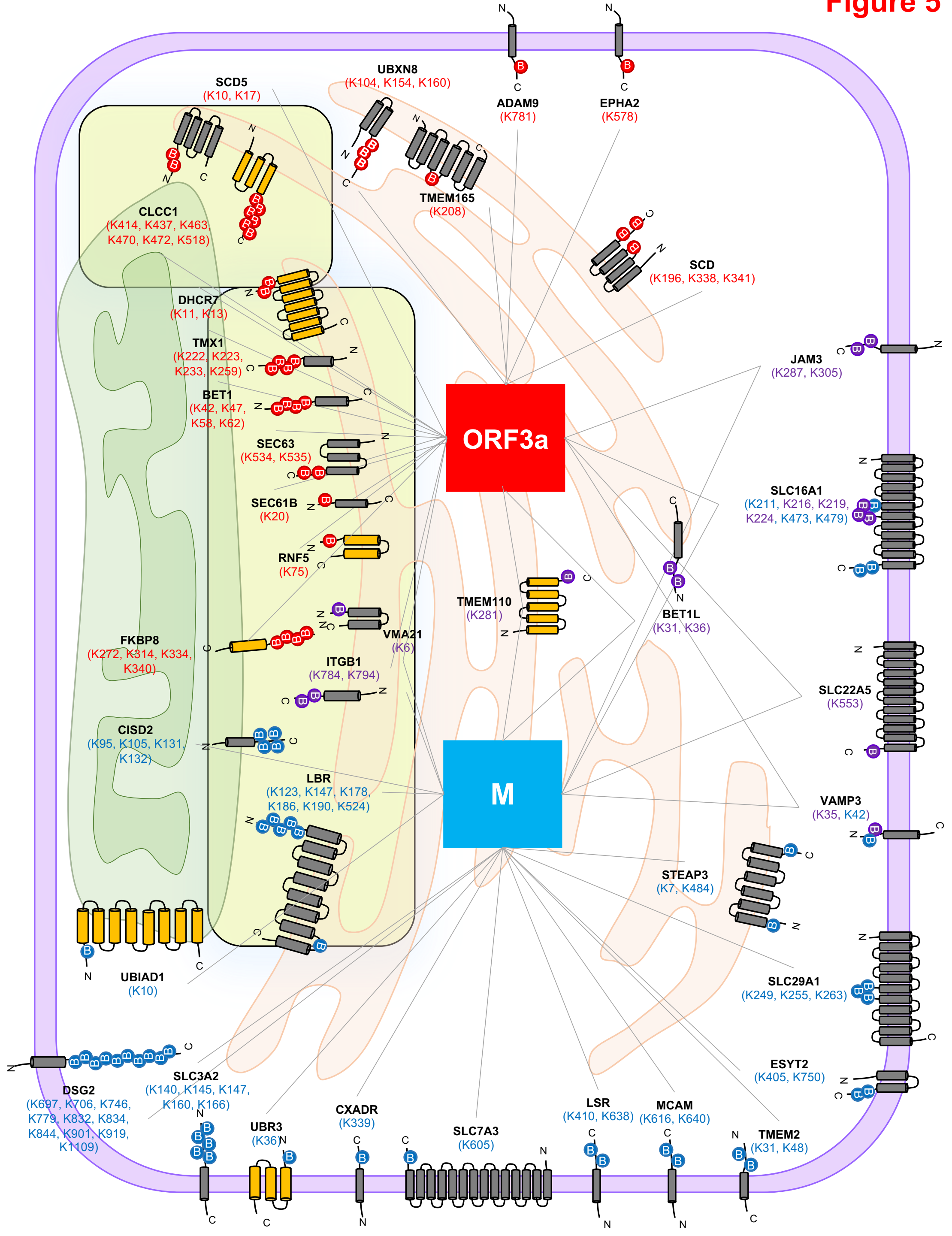


Figure 6
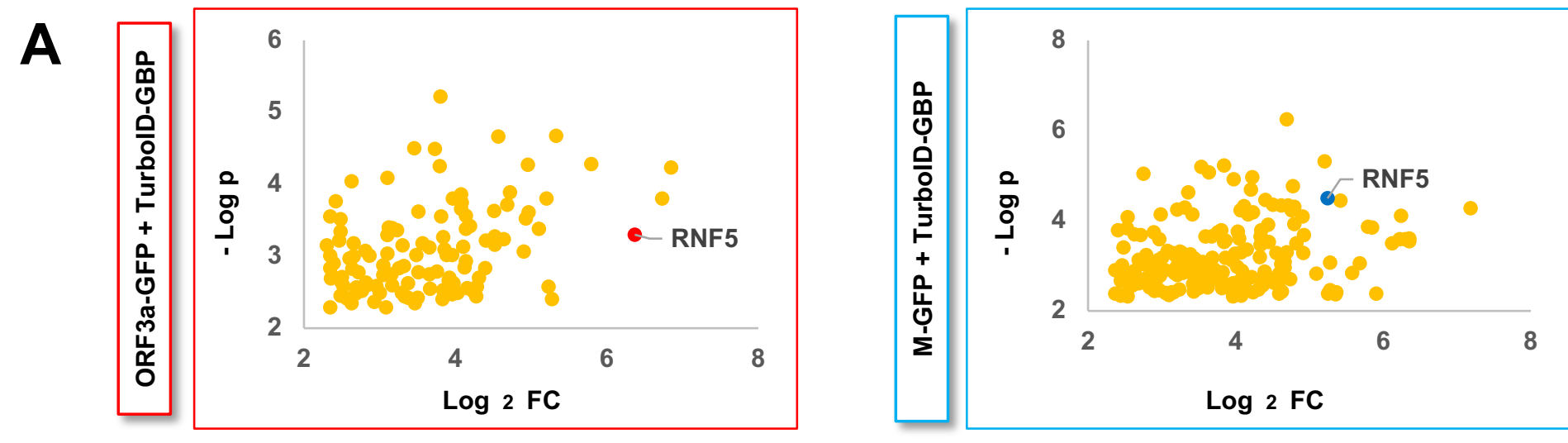

B

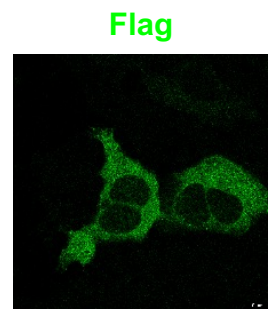

BF

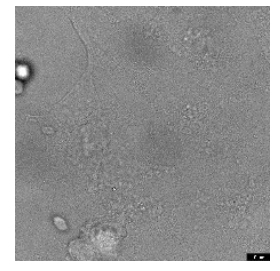

C

Flag

BF

Merged
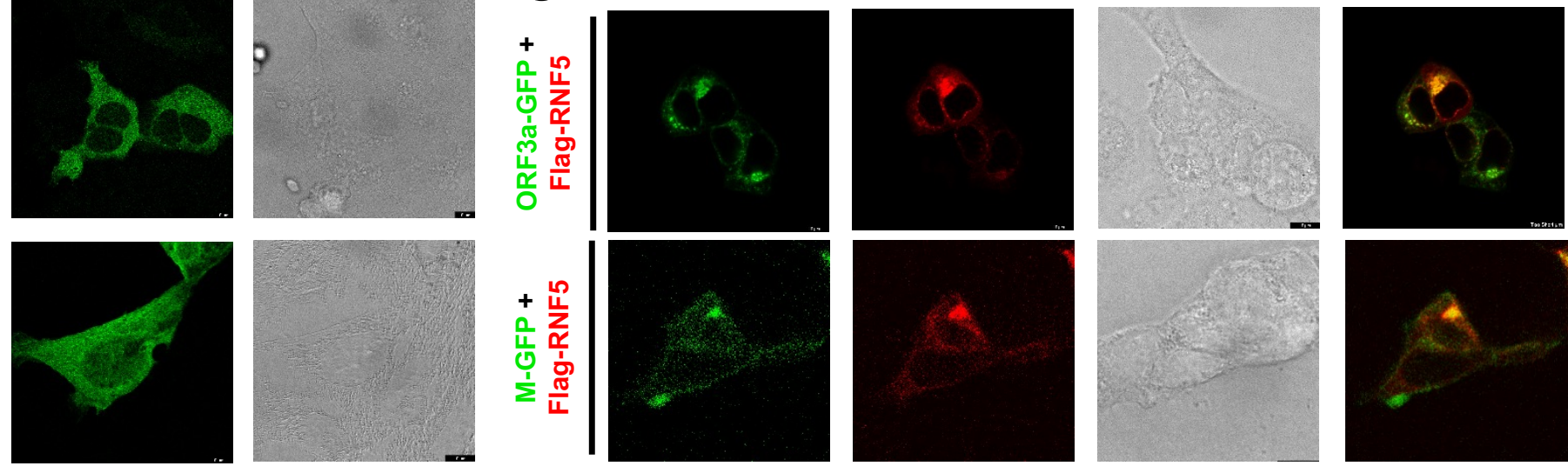

HEK293T

D

: Co-IP using Flag-bead
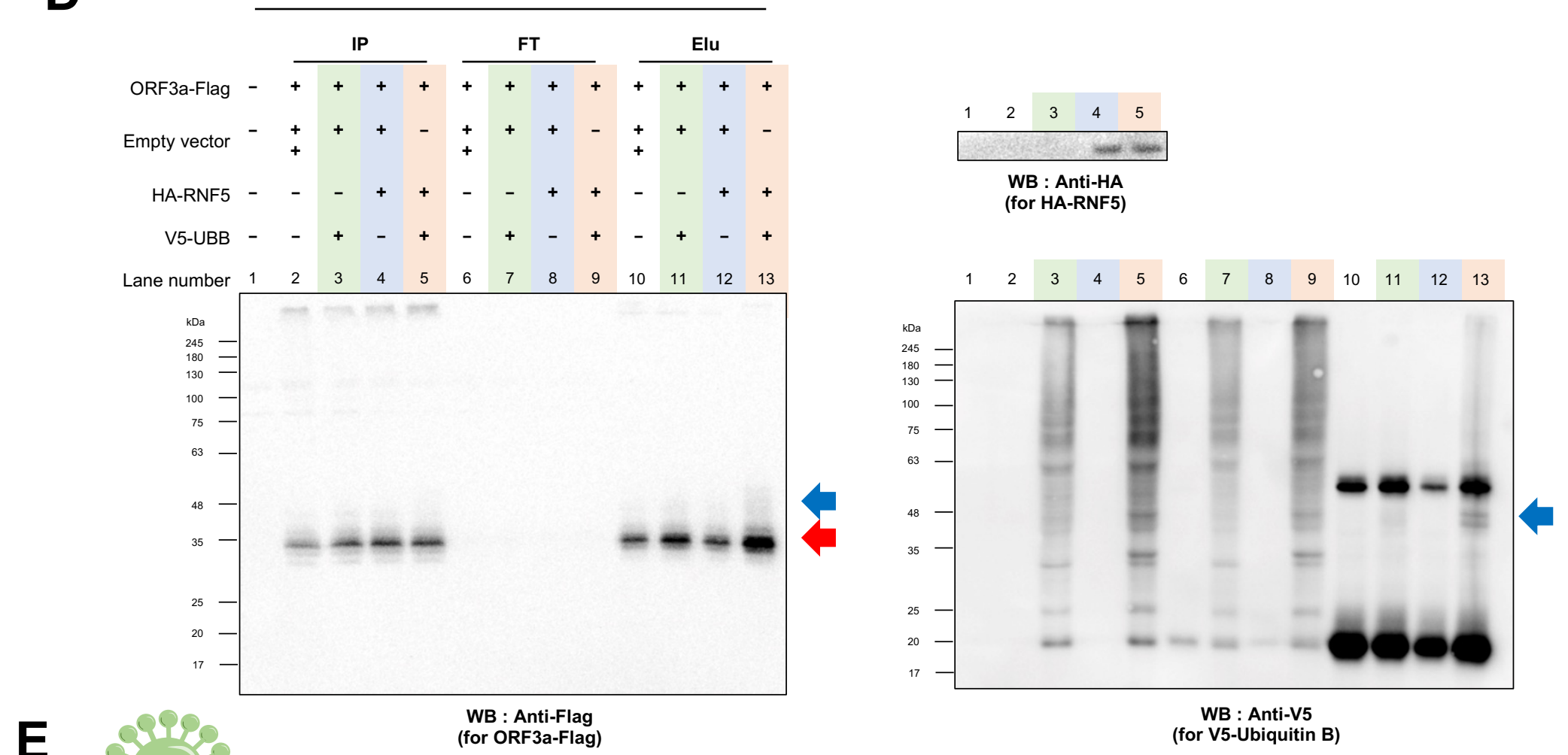

SARS-CoV-2 viral infection

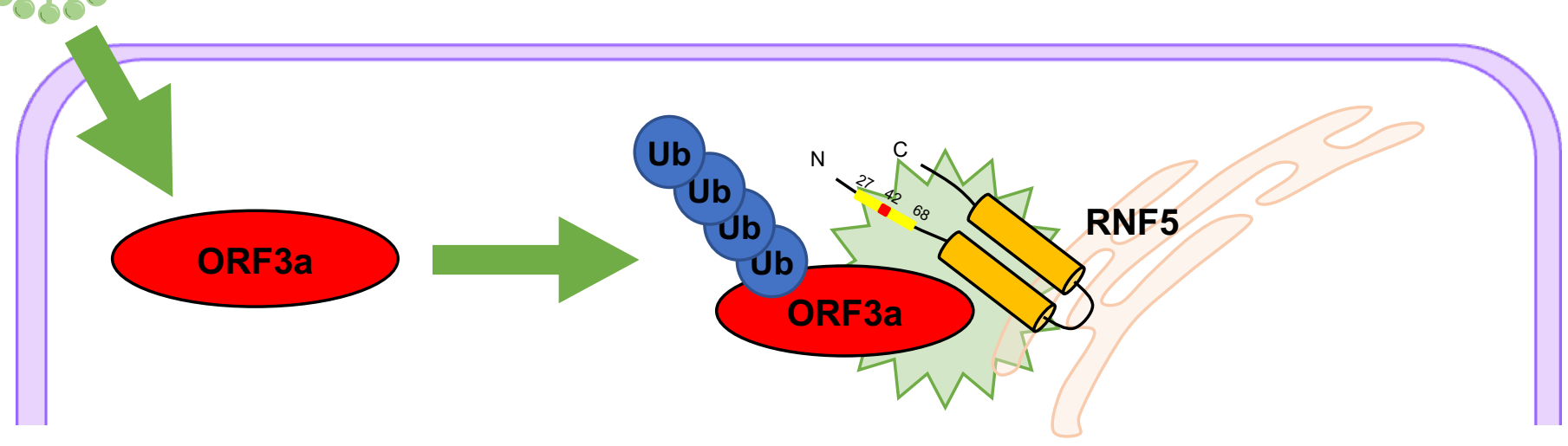


A

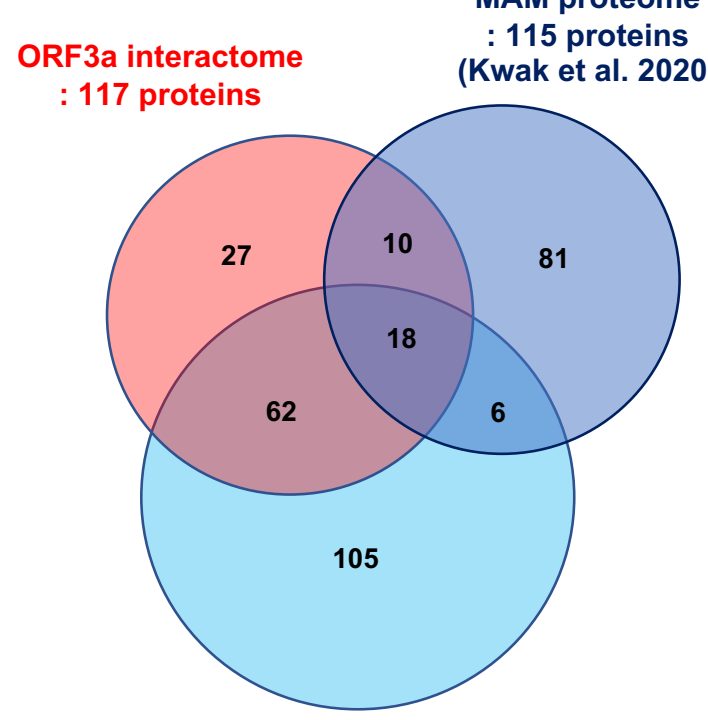

$M$ interactome : 191 proteins
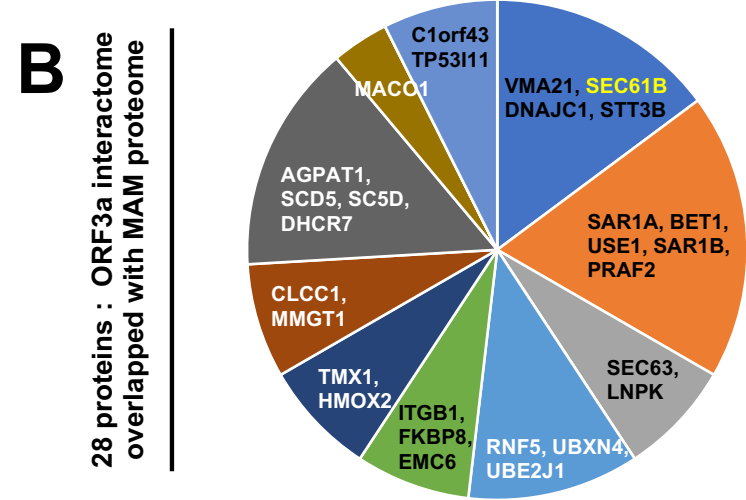

C
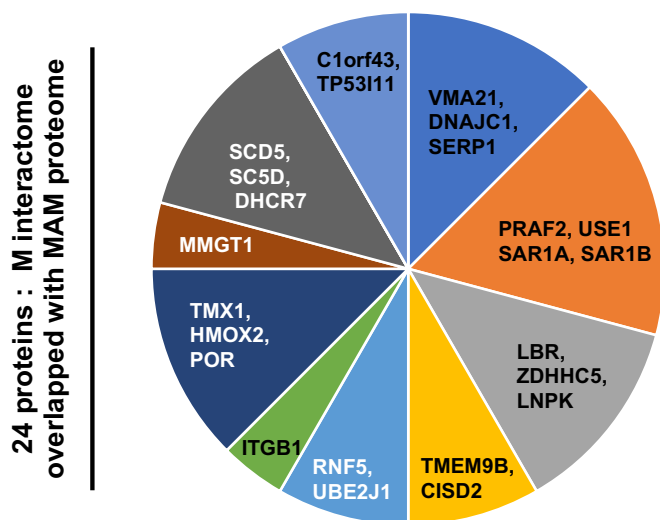

Protein transport and chaperone

Vesicle transport

Membrane integrity

Autophagy/quality control

Protein degradation

Cell cycle/apoptosis

Redox reaction

Ion transport

Lipid synthesis and steroid binding/process

Neuronal activity

Others

D

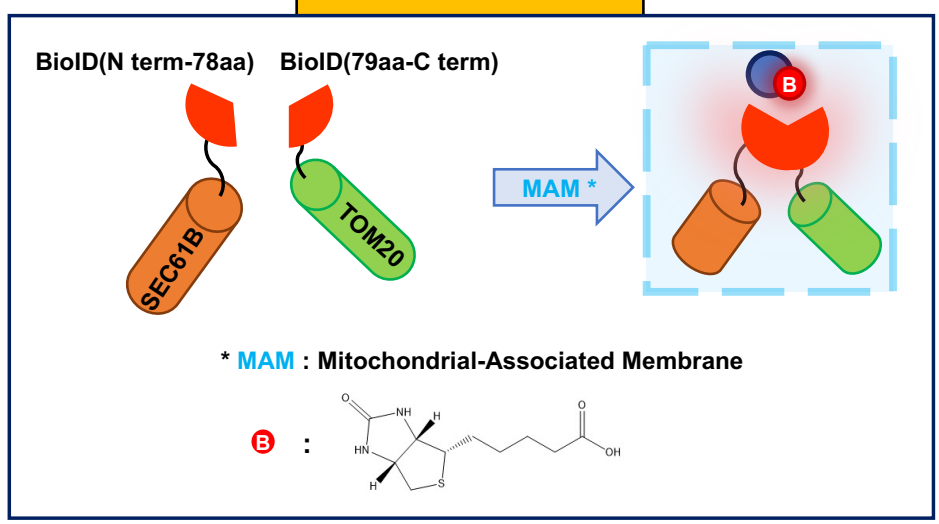

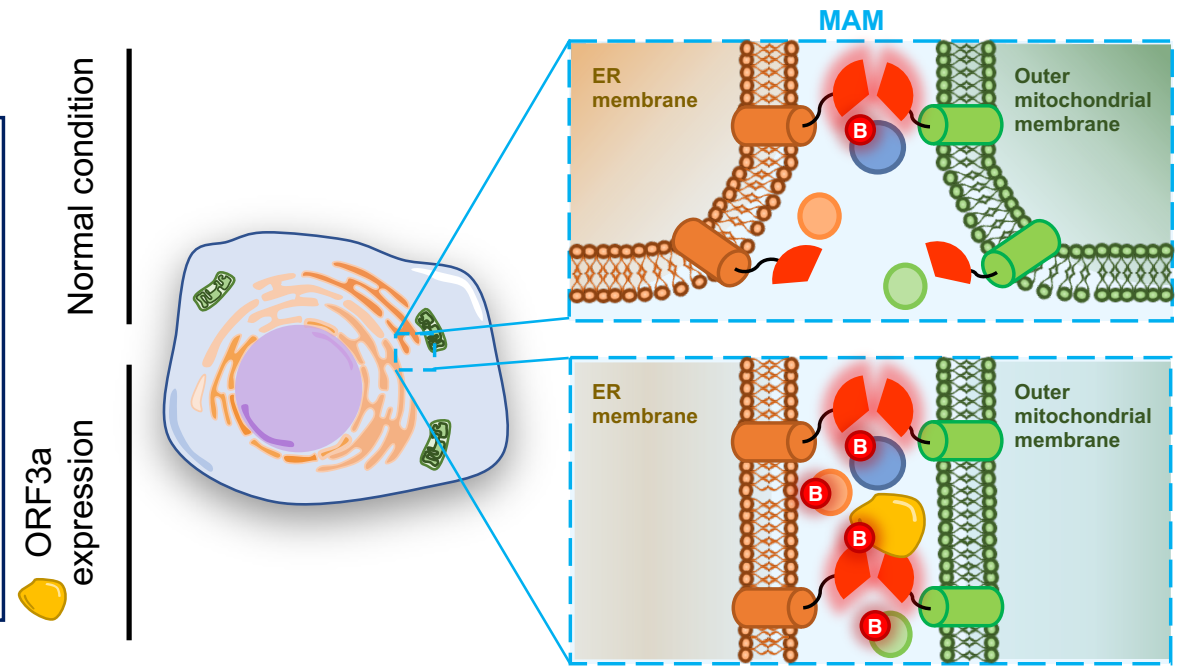

$\mathbf{E}$

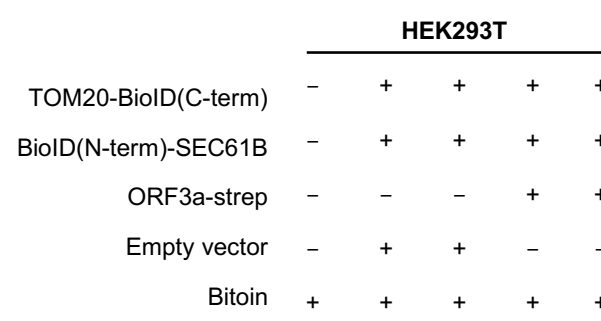

Lane number

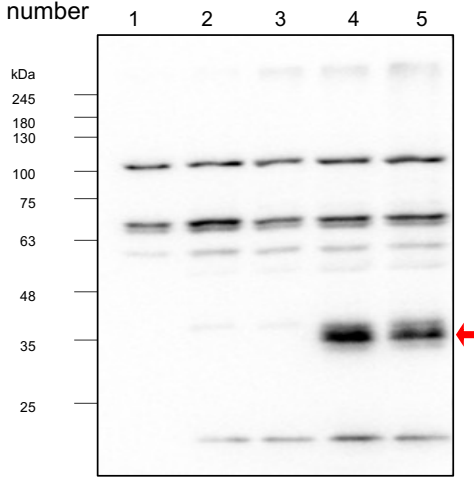

WB : SA-HRP

(short exposure)
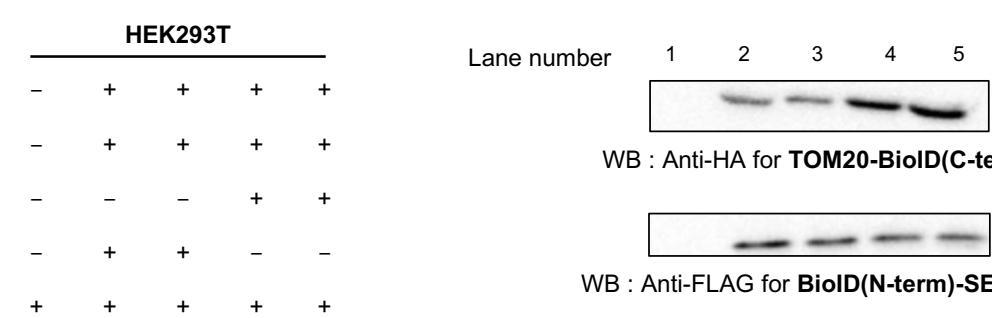

WB : Anti-HA for TOM20-BiolD(C-term)

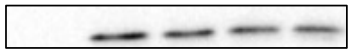

WB : Anti-FLAG for BiolD(N-term)-SEC61B

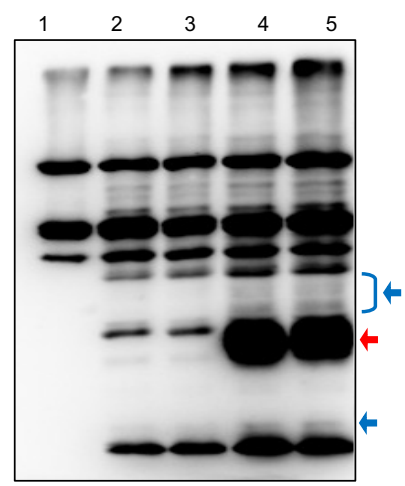

WB : SA-HRP (long exposure)

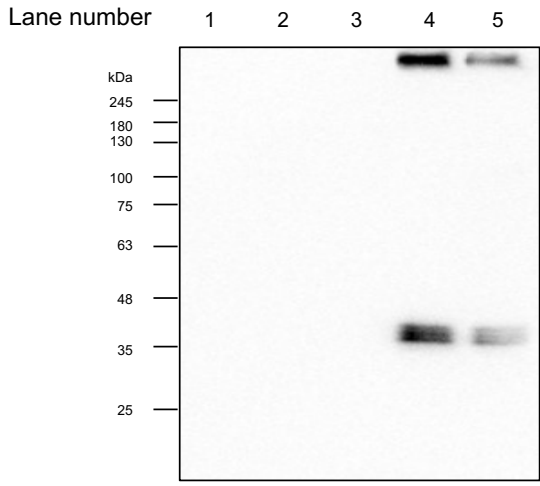

WB : Anti-strep (for ORF3a-Strep) 
$\mathbf{F}$

Identification of secreted proteins using SEC61B-TurboID (iSLET)

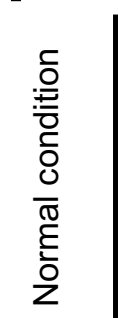

ER-Iutmen
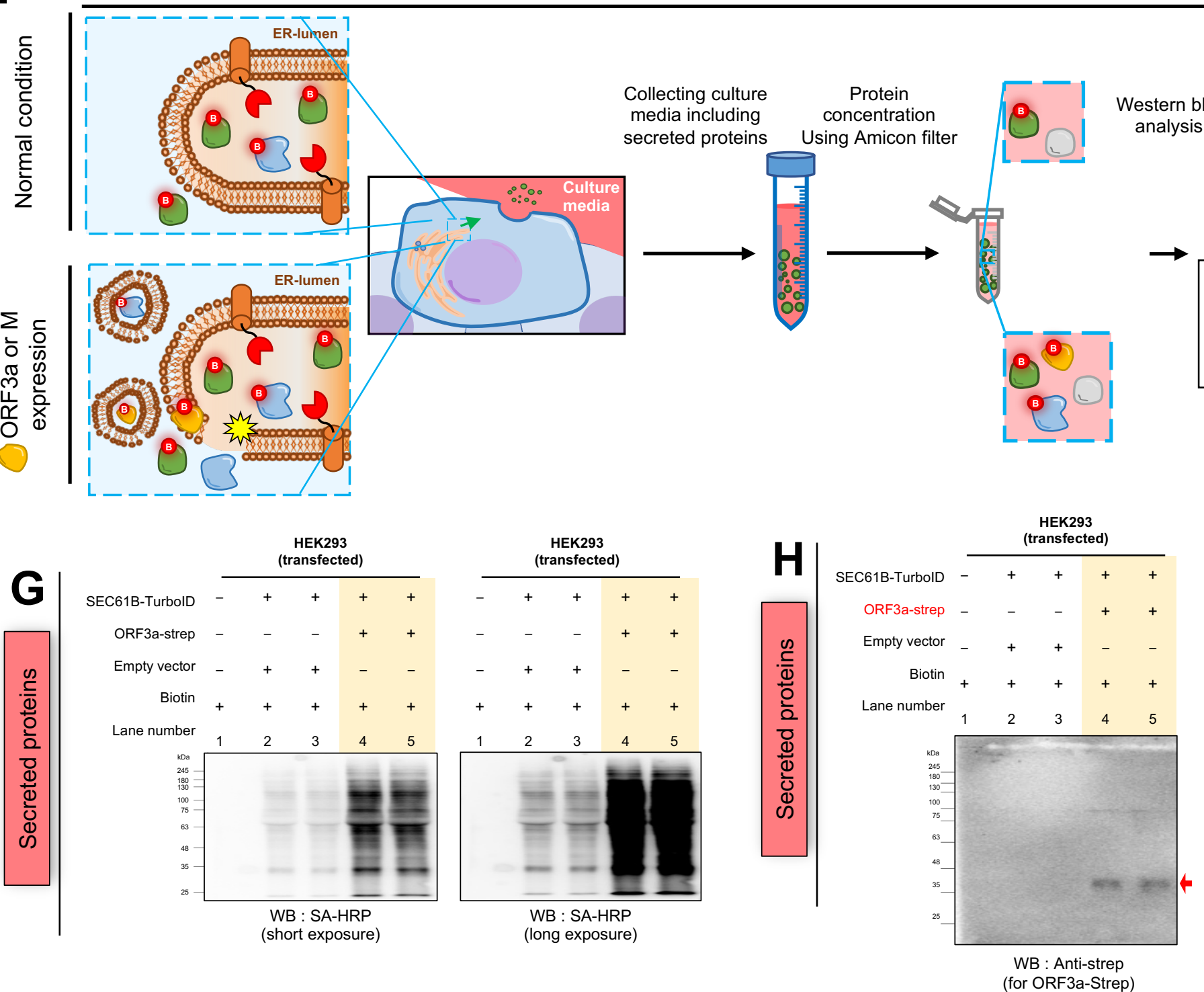